\title{
HACIA LA IGUALDAD DE TRATO Y DE OPORTUNIDADES ENTRE MUJERES Y HOMBRES EN EL ACCESO Y EL DISFRUTE DE LA PENSIÓN DE JUBILACIÓN ${ }^{1}$
}

\author{
Towards equal treatment and opportunities between women \\ and men in access and enjoyment of the retirement pension
}

María del Carmen López Aniorte*

Universidad de Murcia, España

\section{RESUMEN}

Si la actual crisis sanitaria obliga a repensar tanto el modelo económico-productivo espańol como el sistema estatal de protección social y, particularmente, el régimen jurídico de la pensión de jubilación, las mujeres no deberán ser relegadas ni perjudicadas como en otras ocasiones. Bajo este planteamiento, el presente estudio tiene como objetivo analizar, con un enfoque de género, la normativa reguladora de la pensión de jubilación, así como las resoluciones judiciales que la interpretan y aplican. La investigación realizada permitirá conocer tanto las previsiones normativas que discriminan indirectamente a las mujeres en el acceso y el disfrute de dicha pensión, como el nivel de eficacia de las medidas de acción positiva establecidas para reducir la brecha de género en pensiones, aspectos que, en cumplimiento de la normativa internacional y de la Unión Europea, habrán de tenerse en cuenta cuando se aborde la reforma del sistema de protección social español.

Palabras clave: pensión de jubilación, igualdad de trato y oportunidades entre mujeres y hombres, discriminación por razón de sexo, brecha de género en pensiones.

\section{ABSTRACT}

If the current health crisis forces to rethink both the Spanish economic-productive model and the state system of social protection and, particularly, the legal regime of the retirement pension, women should not be relegated or disadvantaged as on other occasions. The objective of this study is to analyze from a gender perspective the regulation of the retirement pension, as well as the judicial resolutions that interpret and apply it. The research carried out will reveal both the norms that indirectly discriminate against women in accessing and enjoying this pension, and the level of effectiveness of positive action measures aimed at reducing the gender gap in pensions, aspects that, in compliance with international and European norms, will have to be taken into account when addressing the next reform of the Spanish social protection system.

Keywords: retirement pension, equal treatment and opportunities between women and men, discrimination based on sex, gender gap in pensions.

${ }^{1}$ El presente trabajo se enmarca en el Proyecto PID2019-104630RB-I00, sobre «El futuro del sistema español de protección social (VI): Soluciones jurídicas a los actuales retos demográficos», financiado por el Ministerio de Ciencia e Innovación, e incluido en la Convocatoria 2019 de Proyectos de I+D+ i - RTI Tipo B.

* Correspondencia a: María del Carmen López Aniorte. c/ Periodista Antonio Herrero, n. ${ }^{0}$ 25-4. ${ }^{\circ}$ P, 30007-Murcia (España) carmenlo@um.es - https://orcid.org/0000-0002-3484-053X

Cómo citar: López Aniorte, María del Carmen. (2020). «Hacia la igualdad de trato y de oportunidades entre mujeres y hombres en el acceso y el disfrute de la pensión de jubilación)"; Lan Harremanak, 43, 120-155. (https://doi.org/10.1387/lan-harremanak.21694).

Recibido: 01 mayo, 2020; aceptado: 25 mayo, 2020.

ISSN 1575-7048 - elSSN 2444-5819 / (c) 2020 UPV/EHU

(c) (i) Esta obra está bajo una licencia

Creative Commons Atribución 4.0 Internacional 


\section{Planteamiento: la originaria y persistente desigualdad de género en materia de protección social}

Se ultima este trabajo en tiempos del confinamiento impuesto por la crisis sanitaria del COVID-19, resultando un contexto propicio para reflexionar acerca de cómo influirán sus efectos económicos y sociales en el futuro del sistema de pensiones español, y particularmente, en la protección social de las mujeres, en un periodo en el que se sitúan en primera línea de una inesperada y dolorosa lucha contra la enfermedad los trabajos de cuidados, feminizados y casi siempre invisibilizados e infravalorados. Todavía vigentes, en buena medida, las medidas laborales y de Seguridad Social diseñadas con motivo de la crisis financiera del 2008, es el momento oportuno de analizar el impacto de las restrictivas reformas adoptadas en materia de pensiones en la protección social de las mujeres de mayor edad y de verificar la eficacia de las acciones positivas diseñadas para reducir la brecha de género en la materia, con el fin de extraer enseñanzas para el momento en que la Unión Europea, en su caso, imponga nuevos límites presupuestarios para atender «de forma prioritaria» el pago de una deuda externa que habrá crecido hasta límites, hasta hace poco tiempo, insospechados.

Es preciso hacer un pequeño recorrido histórico para conocer de dónde venimos y el camino que queda todavía pendiente. A lo largo del siglo XX se incorporaron masivamente las mujeres al trabajo remunerado ${ }^{2}$, y se desarrollaron los modernos sistemas de Seguridad Social. En el caso de España, el tránsito del ámbito de lo privado a lo público (Beard, 2018: 13-51) se vio dificultado durante varias décadas por la aplicación de los principios del Fuero del Trabajo (1938), que mantuvieron confinadas a las mujeres en la esfera privada para el desarrollo de labores reproductivas, domésticas y de cuidado; ello determinó que los seguros sociales construidos durante la dictadura franquista tuvieran como prototipo de sujeto beneficiario al hombre, cabeza de familia y proveedor de ingresos, y reconocieran a aquellas la condición de beneficiarias de prestaciones no causadas por las mismas. Fue necesario esperar al último tercio del siglo $\mathrm{xx}, \mathrm{y}$ de forma particular, a la entrada en vigor de la CE de 1978 —igualdad como valor superior del Ordenamiento Jurídico (art. 1.1), principio/derecho fundamental (art. 14), y mandato a los poderes públicos en pro de la igualdad real y efectiva (art. 9.2) - , para que la participación de las mujeres en el trabajo remunerado se hiciera visible, y empezaran a surgir fisuras en el modelo patriarcal de Seguridad Social. La pensión de viudedad se extendió a los hombres, y las mujeres empezaron a acceder a prestaciones del sistema por derecho propio. Además, con el cambio de siglo, surgieron — con desigual impacto- nuevas prestaciones con

\footnotetext{
2 Este proceso de tránsito de lo privado a lo público constituye la gran revolución del siglo xx, periodo durante el cual la mitad de la población ha conquistado los derechos civiles y políticos (igualdad formal) y ha accedido de forma generalizada al trabajo remunerado.
} 
las que se perseguía, de un lado, paliar la crisis de cuidados que acompañó la incorporación de las mujeres al trabajo asalariado, y de otro, impulsar la corresponsabilidad entre ambos sexos; asimismo, se implementaron prestaciones específicas para las trabajadoras por riesgo durante el embarazo y por riesgo durante la lactancia, y se adoptaron medidas compensatorias encaminadas a reducir la notable brecha de género del sistema de pensiones.

Ahora bien, pese a los cambios normativos producidos, bastante avanzado el primer cuarto del siglo xxi, la igualdad por razón de sexo en el ámbito de la Seguridad Social no se ha alcanzado ni es previsible que se logre a medio plazo, como acreditan los datos sobre afiliación, cuantía de las pensiones y bases de cotización ofrecidos por la Secretaría de Estado de la Seguridad Social referidos a principios de marzo de $2020^{3}$. En ese momento — todavía no había estallado la crisis sanitaria y laboral que llegó semanas después- más de 8,9 millones de trabajadoras estaban afiliadas a la Seguridad Social, representando el $46,64 \%$ del total de la ocupación; y 1,89 millones de mujeres se encontraban en situación de desempleo frente al 1,35 millones de hombres. La pensión media mensual de los hombres era de $1.225 €$ frente a los $803 €$ en el caso de las mujeres; concretamente, la pensión de jubilación media masculina era de $1.332,35 €$ y la femenina de 877,39 € (esta última suponía el 65,8\% de la cuantía de la primera), brecha similar a la de otros países de la Unión Europea (Signorini, 2020: 1-13) las mujeres representaban más del $92 \%$ de las pensiones de viudedad y el $68,5 \%$ de las prestaciones a favor de familiares (todas ellas de baja cuantía); y el 30\% del total de las pensiones percibidas por las mujeres requerían del complemento a mínimos, frente al $17 \%$ en el caso de las percibidas por hombres.

En cuanto a las bases de cotización — que condicionarán la cuantía de las pensiones futuras-, en marzo de 2020 la base de cotización media de las mujeres alcanzaba los $1.662,7 €$ frente a los $1.984,7 €$ de media en el caso de los hombres, lo que refleja la gran brecha salarial que persiste entre ambos sexos; brecha en la que incide - sin ánimo exhaustivo- el altísimo peso de la contratación a tiempo parcial en las mujeres - estas ocupan el $74 \%$ del total de esta modalidad contractual-, el techo de cristal, y la reducida remuneración de los trabajos feminizados (al servicio del hogar familiar, recolección en el sector agrario, camareras de piso, cuidadoras profesionales y no profesionales de dependientes...). Al menor salario se suma la mayor precariedad e intermitencia del trabajo femenino, con entradas y salidas frecuentes del mercado laboral (alta temporalidad, menor tasa de actividad...), y la feminización del disfrute de las excedencias por cuidado familiar (de las 59.446 registradas a principios de

\footnotetext{
3 Disponible en https://revista.seg-social.es/2020/03/06/la-mujer-en-la-seguridad-social-breveradiografia-de-situacion/ (accedido: 27-3-2020).

4 Particularmente, en Italia, la pensión media de los jubilados es de $1.669 €$ y la de las jubiladas de $1.126 €$, resultando estas últimas el $67,5 \%$ de las primeras.
} 
marzo de 2020, 52.889 correspondieron a mujeres, lo que supone el 86,96\%, del total), circunstancias que dificultarán a medio y largo plazo el cumplimiento de los requisitos de acceso a las pensiones por parte de las mujeres y darán lugar a prestaciones más reducidas 5 .

\section{La obligación legal de incorporar la perspectiva de género en el diseño de la normativa de seguridad social y en su aplicación}

Como se ha señalado en el apartado anterior, la diferencia entre sexos en materia de pensiones continúa siendo muy amplia, principalmente, por la persistencia de dos grandes brechas de género, la laboral y la de cuidados, siendo la segunda - vinculada a estereotipos culturales - la principal causa de la primera $^{6}$. La combinación de ambas trae consigo salarios más bajos que dan lugar a bases de cotización más reducidas y vidas laborales interrumpidas por un desigual reparto del trabajo de cuidados dentro la familia ${ }^{7}$, elementos que se traducen en pensiones femeninas más exiguas; aspectos que determinan un mayor índice de pobreza femenina durante todas las etapas vitales ${ }^{8}$.

Pero las dos brechas señaladas no son las únicas circunstancias responsables de la desigualdad entre ambos sexos. Esta también puede ser imputable al diseño androcéntrico del Derecho (Lousada, 2016: 39; Smart, 1994: 173), y a la ausencia de un enfoque de género en quienes lo interpretan y aplican. Así sucede, por ejemplo, cuando en la regulación de las prestaciones del sistema se mantiene como referente un modelo masculino de producción en el que no se reconoce ni

5 Los datos contenidos en este párrafo proceden de la Secretaría de Estado de la Seguridad Social; disponibles en https://revista.seg-social.es/2020/03/06/la-mujer-en-la-seguridad-social-breveradiografia-de-situacion/ (accedido: 27-3-2020).

6 Los estereotipos sexistas son los determinantes de que el rol de cuidadoras atribuido desde siempre a las mujeres se mantenga, imponiéndoles la doble jornada, expulsándolas del mercado laboral o conduciéndolas a ejercer los derechos de conciliación laboral y familiar; determinando la feminización de las profesiones relacionadas con el cuidado; relegando a las mujeres a las categorías más bajas del escalafón profesional; y manteniéndolas alejadas de los ámbitos científicos y tecnológicos.

7 Tal como señala el Informe de la OIT Care work and care jobs for the future of work (2018), las mujeres realizan el $76,2 \%$ de todo el trabajo de cuidados no remunerado a nivel mundial, disponible en https://www.ilo.org/global/publications/books/WCMS_633135/lang--en/index.htm (accedido: 30-03-2019).

8 Sobre la brecha salarial a nivel europeo (del $16 \%$, en cuanto a la remuneración por hora), sus causas, y su incidencia en la brecha en pensiones (de un 37\%), véase la Resolución del Parlamento Europeo, de 30 de enero de 2020, sobre la brecha salarial de género (2019/2870(RSP) en la que se contienen relevantes propuestas para erradicar la brecha salarial, dirigidas a la Comisión y a los Estados miembros. Véase también, EIGE (European Institute for Gender Equality), 2019 (https://eige. europa.eu/gender-equality-index/2019, en línea, fecha de consulta: 16 de noviembre de 2019), conforme al cual, España ocupa el puesto 9 en el Índice de Igualdad de Género que analiza los 28 países de la UE, alcanzando un 70,1 sobre 100 , y superando la media europea $(67,4)$. 
valora el trabajo de cuidados, ni las profesiones con amplia presencia femenina, ni las vicisitudes que pueden sufrirse durante el periodo de gestación y lactancia, ni los riesgos y enfermedades profesionales propias de las actividades desarrolladas mayoritariamente por mujeres. También es responsable el ordenamiento jurídico de la desigualdad cuando no se adoptan medidas normativas eficaces para garantizar la corresponsabilidad y el acceso de las mujeres a los puestos de directivos, o para eliminar la brecha salarial de género. Y, en fin, se propicia la desigualdad cuando los órganos administrativos o judiciales no aplican el principio de igualdad de trato y de oportunidades entre hombres y mujeres en la interpretación y aplicación del Derecho de la Seguridad Social.

La falta de perspectiva de género en el diseño del sistema español de Seguridad Social (Molina, 2020: 2-5) ha quedado reflejada en distintos pronunciamientos del propio TJUE al declarar discriminatorias algunas de sus normas [entre las sentencias más recientes, se encuentran las de 22 de noviembre de 2012 (asunto Elbal Moreno), 9 noviembre 2017 (C-98/2015), 8 de mayo de 2019 (asunto Villar Láiz), y 12 de diciembre de 2019 (asunto WA/Instituto Nacional de la Seguridad Social)]; lo que no deja de ser paradójico puesto que ha sido la propia Unión Europea la que ha impuesto a España «recomendaciones» para la superación de los efectos de la crisis económica-financiera, de alto calado constitucional (reforma del art. $135 \mathrm{CE}$ ), que se han traducido en un endurecimiento de las reglas de cálculo o revalorización de las pensiones y en el retraso de la edad de jubilación, medidas que producen efectos especialmente perjudiciales para las trabajadoras, debido a sus trayectorias laborales intermitentes y precarias.

Para garantizar la igualdad real y efectiva de hombres y mujeres en el ámbito de la Seguridad Social, la normativa en la materia ha de incluir la perspectiva de género, como exigen el art. 19 de la Ley Orgánica 3/2007, de 22 de marzo, para la igualdad efectiva de mujeres y hombres (LOIMH) y el RD 931/2017, de 27 de octubre ${ }^{9}$. En atención a esta normativa, el Informe de Evaluación y Reforma del Pacto de Toledo de 201110 , en su Recomendación 17.a , respalda la adopción de

\footnotetext{
9 En concreto, el art. 19 LOIMH prevé que los proyectos de disposiciones de carácter general —así como los planes de especial relevancia económica, social, cultural y artística que se sometan a la aprobación del Consejo de Ministros- deberán incorporar un informe sobre su impacto por razón de género; por su parte, el RD 931/2017, de 27 de octubre, en el que se regula la memoria del análisis de impacto normativo que debe acompañar a los anteproyectos de ley y proyectos de reales decretos-leyes, reales decretos legislativos y normas reglamentarias, que dicha memoria debe contemplar un apartado referente a «impacto por razón de género», que "analizará y valorará los resultados que se puedan seguir de la aprobación del proyecto desde la perspectiva de la eliminación de desigualdades y de su contribución a la consecución de los objetivos de igualdad de oportunidades y de trato entre mujeres y hombres".

${ }_{10} \mathrm{El} \mathrm{Informe} \mathrm{puede} \mathrm{verse} \mathrm{en,} \mathrm{http://www.seg-social.es/wps/wcm/connect/wss/837109f0-e8fa-}$ 47fb-b878-668afc1 bca1e/Informe+Pacto+de+Toledo+2011..pdf?MOD=AJPERES\&CVID=, en línea, fecha de consulta: 07-04-2020.
} 
medidas dirigidas a la equiparación real de salarios entre sexos, «por su incidencia directa en los futuros derechos sociales, así como la valoración de la dimensión de género en materia de pensiones y la consideración en la carrera de cotización de las mujeres de las diversas circunstancias que pueden incidir en ellas", además de aquellas iniciativas que ayuden a las mujeres «a complementar sus aportaciones económicas con otros elementos, con el objeto de configurar derechos de pensión propios».

Pero, además, es necesario que la perspectiva de género también alcance a quienes aplican e interpretan las normas de Seguridad Social (Lousada, 2020: 11-155), como requieren distintos instrumentos de la Unión Europea e internacionales, así como normas internas. Entre aquellos, se encuentran las Directivas 79/7/CEE del Consejo, de 19 de diciembre de 1978, relativa a la aplicación progresiva del principio de igualdad de trato entre hombres y mujeres en materia de Seguridad Social, y 2006/54/CE del Parlamento Europeo y del Consejo, de 5 de julio de 2006, relativa a la aplicación del principio de igualdad de oportunidades e igualdad de trato entre hombres y mujeres en asuntos de empleo y ocupación.

Asimismo, es muy relevante la Convención sobre la eliminación de todas las formas de discriminación contra la mujer de 18 de diciembre de 1979 $(\mathrm{CEDAW})^{11}$, cuyo art. 15.2 señala que los Estados parte han de reconocer a las mujeres «un trato igual en todas las etapas del procedimiento en las cortes de justicia y los tribunales»; a partir de lo establecido en la Convención, el Comité para la eliminación de todas las formas de discriminación contra la mujer (el CEDAW) ha generado un relevante cuerpo doctrinal sobre estereotipos de género en la impartición de justicia - con eficacia en nuestro orden interno ${ }^{12}$ cristalizado en la Recomendación general núm. 33 sobre el acceso de las mujeres a la justicia (de 2015).

En el ámbito del Consejo de Europa, el Plan de Acción para fortalecer la independencia judicial y la imparcialidad 2016-2021, dirige su acción 2.4 a "combatir la influencia perjudicial de los estereotipos en la toma de decisiones judiciales» ${ }^{13}$; y la Estrategia para la igualdad de género 2018-2023 $3^{14}$, tiene entre sus propósitos y objetivos estratégicos prevenir y luchar contra los estereotipos

${ }^{11} \mathrm{El}$ art. 5.a) de la CEDAW establece que los Estados Partes tomarán todas las medidas apropiadas para «modificar los patrones socioculturales de conducta de hombres y mujeres, con miras a alcanzar la eliminación de los prejuicios y las prácticas consuetudinarias y de cualquier otra índole que estén basados en la idea de la inferioridad o superioridad de cualquiera de los sexos o en funciones estereotipadas de hombres y mujeres».

12 Véase, STS (Contencioso-Administrativo) de 17 de julio de 2018 (Rec. 1002/2017).

13 Plan d'action du Conseil de l'Europe pour renforcer l'indépendance et l'impartialité du pouvoir judiciair, en línea, https://rm.coe.int/1680700286, fecha de consulta: 10 de abril de 2020 .

14 Puede verse en, https://rm.coe.int/estrategia-de-igualdad-de-genero-del-coe-esmsg/16808ac960Una, fecha de consulta: 10 de abril de 2020 . 
de género y el sexismo (objetivo 1), garantizar el acceso igualitario de la mujer a la justicia (objetivo 3), y conseguir la transversalidad de género en todas las políticas y medidas (objetivo 3).

Por su parte, el Tribunal Europeo de Derechos Humanos, merced a una interpretación del Convenio para la Protección de los Derechos Humanos y de las Libertades Fundamentales (1950) como «instrumento vivo», está incorporando en los últimos tiempos el enfoque de género en sus sentencias, por ejemplo, al circunscribir los derechos de conciliación dentro del ámbito del derecho a la vida privada y familiar - art. 8- y a la no discriminación por razón de sexo - art. 14- (sentencia de 22 de marzo de 2012, Konstantin vs. Rusia), o al esbozar el concepto de discriminación múltiple (sentencia de 25 de julio de 2012, B.S. contra España). Y, en fin, sobre la actuación del TJUE como «instrumento corrector» de discriminaciones directas o indirectas por razón de sexo de la normativa de sus Estados Miembros (particularmente, de la normativa de Seguridad Social española), ya se han señalado algunos ejemplos más arriba.

En el ámbito interno, el art. 4 LOIMH prevé que la «igualdad de trato y de oportunidades entre hombres y mujeres es un principio informador del ordenamiento jurídico y como tal se integrará y observará en la interpretación y aplicación de las normas jurídicas»; y su art. 15 dispone que el «principio de igualdad de trato y oportunidades entre mujeres y hombres informará, con carácter transversal, la actuación de todos los Poderes Públicos», debiendo las Administraciones Públicas integrar dicho principio «de forma activa, en la adopción y ejecución de sus disposiciones normativas, en la definición y presupuestación de políticas públicas en todos los ámbitos y en el desarrollo del conjunto de todas sus actividades». Por lo demás, la aplicación de la perspectiva de género a las resoluciones judiciales es un mandato imperativo que emana de la sumisión del poder judicial al imperio de la ley (art. $117 \mathrm{CE}$ ).

Partiendo del presupuesto de que, tanto los informes de impacto de género de las iniciativas normativas como la integración del principio de igualdad de trato y de oportunidades entre hombres y mujeres en la interpretación y aplicación de las normas jurídicas tienen carácter preceptivo (Poyatos, 2018: 7), no es aceptable que, con demasiada frecuencia, dichos informes incumplan los objetivos descritos, limitándose a la mera observancia formal de la exigencia normativa. Como tampoco es razonable que, a día de hoy, algunos órganos judiciales obvien la perspectiva de género en resoluciones en las que procede aplicar esta técnica, como ha advertido el CEDAW ${ }^{15}$, sin duda por una falta de capacitación

15 Véase el Dictamen del Comité para la Eliminación de la Discriminación contra la $\mathrm{Mu}$ jer (CEDAW) en virtud del Protocolo Facultativo de la Convención de la ONU sobre la eliminación de todas las formas de discriminación contra la mujer ( $58^{\circ}$ período de sesiones), Comunica- 
en la materia que venía siendo reclamada por distintos instrumentos internacionales $^{16}$, y a la que finalmente ha dado respuesta la reforma de 2018 de la Ley Orgánica del Poder Judicial para establecer la obligatoriedad de la formación en igualdad de género para el acceso a la carrera judicial y en la formación continua, pero olvidando la capacitación de quienes integran el Tribunal Supremo y el Tribunal Constitucional; omisión desafortunada al ser de estos órganos de los que emanan la doctrina jurisprudencial y la doctrina constitucional, vinculantes para los órganos judiciales.

En relación con la aplicación del principio de igualdad en las resoluciones judiciales, el Tribunal Constitucional (TC), en su sentencia 3/2007, de 15 de febrero, ya señaló que los «órganos judiciales no pueden ignorar la dimensión constitucional de la cuestión ante ellos suscitada y limitarse a valorar, para excluir la violación del art. 14, si la diferencia de trato tiene en abstracto una justificación objetiva y razonable, sino que han de efectuar su análisis atendiendo a las circunstancias concurrentes». Este planteamiento del TC es adecuado a un concepto moderno de discriminación por razón de sexo basado más en la subordinación que en la comparación, y que define aquella como toda situación de subordinación de las mujeres respecto a los hombres a causa de los prejuicios de género (Lousada, 2020: 31). Conforme a esta noción, es cada vez mayor el número de sentencias dictadas en el orden social en las que se aplica la técnica de juzgar con una perspectiva de género, en supuestos en los que están presentes relaciones asimétricas de poder derivadas de la persistencia de estereotipos sexistas. Esta técnica permite en primer término «detectar si en un determinado conflicto jurídico está influyendo la existencia de un estereotipo de género que puede estar generando una diferencia de oportunidades o derechos", y, una vez constatada su existencia, hace posible su erradicación «de la aplicación o interpretación de la norma corrigiendo y compensando el desequilibrio que haya podido ocasionar» (Jiménez, 2018).

Con la técnica de juzgar con perspectiva de género, tal como precisa la STS de 21 de diciembre de 2009 (Rec. 201/2009; Ponente: María Lourdes Arastey Sahun) — sentencia pionera en la materia-, se supera el principio de igualdad formal, mayoritariamente ya alcanzado, pero insuficiente, y que implica la prohibición de discriminación, «para acoger el más moderno de igualdad de oportunidades que incluye nuevas instituciones antidiscriminatorias, medidas de

ción núm. 47/2012 (disponible en http://web.icam.es/bucket/Dict\%C3\%A1men\%20CEDAW\%20 \%C3\%81 ngela\%20Gonz\%C3\%A1lez\%20Carre\%C3\%B1o.pdf, accedido: 25-08-2017), que formula al Estado español la recomendación de proporcionar «formación obligatoria a los jueces y personal administrativo competente sobre la aplicación del marco legal en materia de lucha contra la violencia doméstica».

16 Véanse la Recomendación general núm. 33 del CEDAW sobre el acceso de las mujeres a la justicia (2015), apartados 26 a 29, y el Plan de acción del Consejo de Europa para reforzar la independencia e imparcialidad del poder judicial, cit., Acción 2.4 . 
acción positiva y el control de la discriminación indirecta» ${ }^{17}$. En la jurisdicción social esta técnica ha sido aplicada por otras sentencias posteriores del Tribunal Supremo, tales como las de 26 de septiembre de 2018 (Rec.1352/2017; Ponente: María Lourdes Arastey Sahun), 29 de enero de 2020 (Rec. 201/2009; Ponente: María Lourdes Arastey Sahun $)^{18}$ - sobre discriminación por asociación (Ferrando, 2020: 1-23) - y 6 de febrero de 2020 (Rec. 3801/2017; Ponente: María Luisa Segoviano Astaburuaga); así como, entre otras, por las SSTSJ Galicia de 14 de octubre de 2016 (Ponente: Fernando Lousada Arochena) ${ }^{19}$, Canarias/Las Palmas, de 7 de marzo de 2017 (Ponente: Gloria Poyatos Matas) ${ }^{20}$, y La Rioja de 10 de enero de 2019 (Ponente: Cristóbal Iribas Genua) ${ }^{21}$.

Tímidamente, el enfoque de género también empieza a contemplarse en alguna resolución del TC sobre protección social. Aunque dicha perspectiva está bastante alejada del hilo argumental de la STC 111/2018, de 17 de octubre, que deniega a un padre la prestación de paternidad en términos equiparables a la de maternidad (no así del voto particular a cargo de la Magistrada Balaguer Callejón), la STC 91/2019, de 3 de julio, sí incorpora la perspectiva de género, siendo uno de los aspectos novedosos de la misma que fuera el propio Tribunal Constitucional quien tomara la iniciativa y planteara una cuestión interna de inconstitucionalidad, a propósito de un recurso de amparo de un profesor de universidad con trabajo a tiempo parcial.

17 En esta sentencia, dictada en unificación de doctrina, se reconoce a la recurrente pensión de invalidez del extinguido SOVI — que le había sido denegada por el INSS por falta de carencia-, computando como cotizados asimilados por parto, los 112 días de bonificación que establecía la DA 44 LGSS, en el entendimiento de que cuando dicha DA, introducida por la LOIMH, se refiere a "cualquier régimen de Seguridad Social», ello "no puede ser interpretado en una literalidad estricta" porque la finalidad del precepto «no es mejorar la vida laboral de las trabajadoras que hayan cotizado a la seguridad social, sino beneficiar a todas las mujeres cuando hayan de obtener beneficios prestacionales o sociales derivados de su actividad laboral, pues esa actividad laboral es la que se ha visto afectada por la circunstancia derivada de su sexo".

18 Sentencia muy relevante, firmada por la misma Magistrada Ponente que la comentada en la nota anterior, e igualmente referida al SOVI. Esta resolución, que acoge la construcción jurisprudencial del TJUE de la discriminación por asociación [SSTJUE de 17 de julio de 2008, Asunto (C-303/06, caso Coleman) y de 16 de julio de 2015 (C83/14)], desestima el recurso de casación para la unificación de doctrina interpuesto por el INSS contra la STSJ de canarias/Las Palmas, de 2 de mayo de 2017 (Ponente: Gloria Poyatos Matas), que había reconocido el derecho a una mujer a percibir una pensión en favor de familiares por la muerte de su madre, pensionista del antiguo régimen SOVI que no reconocía dicha pensión. El Alto Tribunal, partiendo de la abrumadora feminización de las pensiones del vejez del SOVI (todas ellas de baja cuantía), rechaza que pueda efectuarse una aplicación literal de la norma cuando la misma puede tener un evidente impacto negativo sobre un colectivo (discriminación indirecta), y, además, añade que la interdicción de la discriminación no se limita a las personas en las que concurre la condición personal amparada, sino que la protección debe ser aplicable también a quien sufra un trato desfavorable por el mismo motivo pese a no ser la persona sobre la que concurría la situación de discriminación (discriminación por asociación).

19 JUR\2016\249172.

20 JUR\2017\66383.

21 N.o de Recurso: 236/2018. 


\section{La recurrente vulneración el principio de igualdad de trato y de oportunidades en las reformas del sistema de pensiones}

En los últimos tiempos se han producido distintas reformas del sistema de la Seguridad Social, encaminadas a atender sus grandes retos: el envejecimiento de la población; las crisis económicas, que han derivado en recomendaciones de la Unión Europea de estabilidad presupuestaria con exigencia constitucional de subordinación de los derechos sociales al principio de estabilidad (Ortiz, 2016: 135); y la precariedad laboral generalizada —especialmente acentuada en el caso de las mujeres-, con bajos salarios y reducidas cotizaciones.

Las reformas producidas, encaminadas a la reducción del gasto y no a la mejora de los ingresos (Aparicio, 2015: 289), han afectado al requisito de carencia de la pensión de jubilación y a sus reglas de cálculo y revalorización; han establecido límites al complemento por mínimos; y han retrasado la edad de jubilación. Tales medidas han perjudicado especialmente a las trabajadoras (García, 2019: 82), sin que se haya establecido mecanismo compensatorio alguno. Ello denota una falta absoluta de perspectiva de género en el diseño de las normas en las que aquellas medidas se contienen, lo que, a su vez, es indiciario, bien de falta de sensibilización y capacitación de quien legisla sobre los efectos negativos de los sesgos de género en el acceso de las mujeres en condiciones de igualdad al sistema de protección social ${ }^{22}$, o bien de que no constituye una prioridad legislativa la igualdad de trato y de oportunidades entre mujeres y hombres en la materia (o ambas cosas al mismo tiempo).

Junto a las reformas arriba señaladas que, siendo de carácter general, producen un mayor impacto negativo en las mujeres, también se han llevado a cabo otras de tipo sectorial, dirigidas a trabajos feminizados del ámbito de los cuidados, que han supuesto un recorte directo de derechos adquiridos por las mujeres de los sectores más desfavorecidos. En esta categoría se encuadra la eliminación por el Real Decreto-ley 20/2012, de 13 de julio, de la asunción por el Estado de la cotización a las cuidadoras no profesionales de las personas en situación de dependencia, lo que supuso reducir las cerca de 180.000 cuidadoras — mujeres, la inmensa mayoría - con un convenio especial suscrito en julio de 2012, hasta el mínimo de 7.304 en marzo de $2019^{23}$. La medida tuvo un dramático impacto de género, al expulsar del sistema de Seguridad Social a unas 170.000 muje-

${ }^{22}$ La Recomendación general núm. 33 del CEDAW sobre el acceso de las mujeres a la justicia (2015), en sus apartados 30 a 34, recomienda a los Estados Parte que desarrollen experiencia en materia de género, «incluso aumentando el número de asesores en materia de género», y que «integren, en los planes de estudios a todos los niveles educativos, programas educacionales sobre los derechos de las mujeres y la igualdad entre los géneros, incluidos los programas de conocimientos jurídicos».

${ }^{23}$ Cfr., http://prensa.empleo.gob.es/WebPrensa/noticias/seguridadsocial/detalle/3538, en línea, 13-07-2019. 
res, muchas de las cuales, presumiblemente, no se habrían podido incorporar al mercado de trabajo o se habrían visto obligadas a abandonar sus empleos e interrumpir sus carreras de cotización para el desarrollo de un trabajo de cuidados marcado por los roles sociales, e impuesto por la falta de atención institucional a un número cada vez mayor de personas en situación de dependencia.

Siete años después de la medida, el RDL 6/2019, de 1 de marzo, ha recuperado la financiación de las cuotas del convenio especial a cargo del Estado; no obstante, la reforma es de reducido alcance pues sólo afecta a los convenios especiales existentes a la fecha de entrada en vigor del Real Decreto-ley 6/2019 (7.304) y no a los que se extinguieron tras la entrada en vigor del Real Decretoley 20/2012 (170.000).

Mientras no se produzca la completa profesionalización de los servicios de cuidados a personas dependientes y se supere el estereotipo de género que impone los cuidados a las mujeres, la asunción por el Estado de las cotizaciones de las personas cuidadoras no profesionales de quienes se encuentran en situación de dependencia, contribuiría eficazmente a que lucre pensiones de jubilación un número no desdeñable de mujeres con bajos ingresos profesionales, razón por la cual es necesario que la medida se extienda a todo el colectivo.

\subsection{Efectos del endurecimiento del requisito de carencia en las pensiones de jubilación femeninas}

El art. 205.1.b) LGSS exige un período de carencia de 15 años como mínimo (5.475 días efectivamente cotizados), de los cuales al menos 2 años deben estar comprendidos en los 15 inmediatamente anteriores al momento de causar el derecho a la pensión de jubilación o a la fecha en que cesó la obligación de cotizar.

Puede parecer un periodo de carencia reducido, pero lo cierto es que muchas mujeres con lagunas de cotización tendrán dificultades para alcanzar tanto los 15 años de periodo mínimo de cotización como la carencia específica de 2 años en los últimos 15. La observancia de esta segunda exigencia se verá frustrada cuando se haya dejado de trabajar para el cuidado de familiares (en este tramo de edad, previsiblemente se tratará de personas mayores y dependientes), y no sea posible la reincorporación al trabajo con posterioridad.

El requisito de los 15 años de cotización se vio endurecido por la reforma llevada a efecto por la Ley 40/2007, de 4 de diciembre, que excluyó los «días cuota» para el cómputo del período mínimo de cotización de la pensión de jubilación (no así para el reconocimiento de otras prestaciones como la incapacidad permanente, la incapacidad temporal, la viudedad, etc.). Si bien, hasta la entrada en vigor de dicha reforma, la norma exigía — como en la actualidad — una carencia de 15 años para acceder a la pensión de jubilación, la STS 918/1974, 
de 10 de junio (Ponente: Eduardo García-Galán) había concretado que para el cómputo de tal carencia había que tener en cuenta los «días cuota» correspondientes a las pagas extraordinarias (60 días por año). De este modo, bastaba con lograr los 4.700 días efectivos de cotización —algo menos de 13 años trabajados y cotizados - para tener derecho a la pensión de jubilación, en lugar de los 5.475 días que suponen los 15 años. La nueva regulación entró en vigor el 1 de enero de 2008, finalizando su periodo transitorio de aplicación el 1 de enero de 2013.

Como ya se ha señalado, las mujeres se han visto especialmente afectadas por la medida dado que sus carreras de cotización son más cortas que las de los hombres. Ello es debido, no sólo a su actividad laboral intermitente y precaria, con entradas y salidas frecuentes del mercado laboral en los términos ya señalados, sino también a su significativa participación en la economía sumergida. Este último aspecto no es, en absoluto, desdeńable, teniendo en cuenta el alto porcentaje de empleo informal que se mantiene en España, en relación con el empleo total, y del elevado protagonismo que en el mismo presenta la mano de obra femenina ${ }^{24}$, especialmente, en sectores precarizados como el trabajo doméstico, los cuidados personales, la hostelería, y los talleres de confección o de fabricación de calzado ${ }^{25}$. Las medidas de lucha efectiva contra la economía sumergida, no sólo contribuyen a garantizar la sostenibilidad del sistema, sino que permiten que un mayor número de mujeres tenga acceso a una pensión contributiva de jubilación que, tras la reforma de 2007, llevada a cabo ignorando su impacto negativo de género, les resulta más difícil de lucrar.

\subsection{El impacto de género de las medidas encaminadas a retrasar la edad de jubilación y a incentivar el envejecimiento activo}

Ante el significativo incremento de la esperanza de vida en Europa, la Unión Europea viene impulsando medidas encaminadas a favorecer el envejecimiento activo, con el fin lograr un «equilibrio sostenible» entre el tiempo de trabajo y el de jubilación ${ }^{26}$. En cumplimiento de las recomendaciones comunitarias, se han adoptado distintas medidas en España, dirigidas a retrasar la edad de jubilación,

24 UGT-Euskadi: El trabajo invisible: la feminización de la economía sumergida, disponible en http://www.ugteuskadi.org/wp-content/uploads/2017/12/ECONOMIA-SUMERGIDA-WEB. pdf (Accedido: 8-07-2019). Según datos de la OIT correspondientes al año 2018, en España el porcentaje de empleo informal es del 27,3\%, del que un 26,2\% son hombres, y 28,7\% mujeres. Dicho porcentaje es muy elevado — si se compara con el de Francia (9,8\%), Alemania (10,2\%), Bélgica (13,5\%), Portugal (12,1\%) o Italia (19,0\%;), acercándose al de Grecia (32,8\%)—, y castiga especialmente a las mujeres (OIT, Oficina Internacional del Trabajo, Mujeres y hombres en la economía informal: un panorama estadistico, Tercera Edición, Ginebra, 2018, p. 90).

25 https://www.elsaltodiario.com/industria-textil/sumergidas (accedido: 8-07-2019).

26 Véase, El Libro Verde de la Comisión Europea sobre sistemas de pensiones europeos adecuados, sostenibles y seguros (2010), Bruselas, 7.7.2010, COM (2010) 365 final, SEC(2010)830. 
dificultar la jubilación anticipada, y establecer distintas fórmulas de envejecimiento activo que permitan compatibilizar la pensión de jubilación y el trabajo.

Estas reformas no han tenido en cuenta la realidad del trabajo femenino, con frecuencia penoso (es el caso, por ejemplo, de la actividad de las denominadas «kellys»" ${ }^{27}$, del trabajo al servicio del hogar familiar, o del de las cuidadoras profesionales de dependientes en domicilios y en establecimientos especializados) e inadecuado para ser desarrollado a una edad avanzada, ni las especiales dificultades que las mujeres de mayor edad encuentran para mantenerse en el mercado laboral por el efecto de la discriminación múltiple por razón de sexo y edad (Ferrando, 2018: 19-54).

La Ley 27/2011, de 1 de agosto, sobre actualización, adecuación y modernización del sistema de Seguridad Social, aumentó la edad legal de jubilación de forma progresiva, desde los 65 a los 67 años. Conforme al vigente art. 205.1.a) LGSS, la edad general de jubilación son los 67 años; a tal efecto, la edad legal de jubilación se incrementará progresivamente a partir del 1 de enero de 2013, hasta exigirse 67 años en 2027, salvo para quienes en la fecha de la jubilación acrediten 38 años y seis meses cotizados o más, que podrán seguir jubilándose a los 65 años. Por razones ya explicitadas, pocas mujeres podrán acreditar las largas carreras de cotización exigidas para poder jubilarse a los 65 años, viéndose compelidas a hacerlo — cuando el mercado laboral se lo permita - a edades más avanzadas que los hombres; ya en la actualidad, sin haber agotado el periodo transitorio, la edad de jubilación efectiva de las mujeres (62,6 años) es ligeramente superior a la de los hombres $(62,2 \text { años })^{28}$. Ahora bien, muchas mujeres no podrán mantenerse en sus puestos de trabajo a una edad avanza; para ellas, el aumento de la edad legal de jubilación generará penalizaciones cuando, en el mejor de los casos, puedan jubilarse anticipadamente, $y$, en el peor escenario y más probable, resulten expulsadas del mercado de trabajo sin tener derecho a la pensión de jubilación contributiva, y quedando abocadas, en su caso, a la no contributiva, de reducida cuantía.

Las jubilaciones anticipadas fueron modificadas, sucesivamente, por la Ley 27/2011, de 1 de agosto, y por el Real Decreto-Ley 5/2013, de 15 de marzo, normas que endurecieron sus requisitos de acceso, sin tener en cuenta el impacto de género de las medidas adoptadas. Como resultado de los cambios introducidos, el requisito de carencia pasó de 33 años a 35 en la jubilación anticipada voluntaria (art. 208 LGSS), y de 30 a 33 en la involuntaria (art. 207

\footnotetext{
27 Cfr. la STSJ Canarias de 5 de junio de 2018, y particularmente el voto particular emitido por la Magistrada Gloria Poyatos Matas.

${ }^{28}$ Instituto BBVA de PENSIONES: «Edad real y edad legal de jubilación no suelen coincidir. ¿En qué países se jubilan antes y en qué países después?», enero 2019, disponible en https:// www.jubilaciondefuturo.es/es/blog/edad-real-y-edad-legal-de-jubilacion-no-suelen-coincidir-en-quepaises-se-jubilan-antes-y-en-que-paises-despues.html (accedido: 11-7-2019).
} 
LGSS), computando a estos exclusivos efectos, «el período de prestación del servicio militar obligatorio o de la prestación social sustitutoria, con el límite máximo de un ańo", y sin contemplar expresamente el servicio social de las mujeres previsto en el Decreto de 11 de octubre de 1937. La omisión responde a una visión androcéntrica del Derecho que, certeramente, ha sido subsanada por la STS de 6 de febrero de 2020 (Rec. 3801/2017; Ponente: María Luisa Segoviano), dictada en unificación de doctrina ${ }^{29}$, mediante la aplicación del criterio hermenéutico recogido en el art. 4 LOIMH; en esta resolución, se reconoce por primera vez el derecho de una mujer a computar el servicio social para acreditar la carencia necesaria para acceder a la jubilación anticipada, admitiendo el TS respecto de este particular supuesto que «únicamente mediante la aplicación de la perspectiva de género en la interpretación y aplicación del precepto —art. 208.1.b), último párrafo, de la LGSS — se alcanza la igualdad de trato y de oportunidades entre mujeres y hombres, ya que la aplicación literal del mismo conduciría a una violación de dicho principio pues supondría un trato discriminatorio de las mujeres respecto a los hombres» ${ }^{30}$.

Por su parte, la edad que ahora se exige tener cumplida es, respectivamente, de dos y cuatro años inferior a la edad ordinaria de jubilación —es decir, 65 y 63 años-, en la jubilación voluntaria y en la involuntaria, con aplicación de coeficientes reductores por cada trimestre de antelación. Además, en la jubilación voluntaria, se impide el acceso a la misma si tras aplicar los coeficientes reductores el importe de la pensión resultara inferior a la pensión mínima que correspondiese, debiendo complementarse a mínimos, requisito restrictivo que, una vez más, podría discriminar indirectamente a las mujeres afiliadas al Régimen General de la Seguridad Social, al aplicarse a un número mucho mayor de mujeres que de hombres; duda jurídica que ha dado lugar a la Petición de decisión prejudicial presentada por el TSJ Cataluña el 20 de noviembre de 2019 [Instituto Nacional de la Seguridad Social (INSS)/BT-(Asunto C-843/19)].

Es evidente que las reformas introducidas en la materia dificultarán tanto la jubilación anticipada voluntaria, como la involuntaria, convirtiéndolas en re-

${ }^{29}$ La sentencia recurrida fue la STSJ Cataluña de 15 de junio de 2017 (Rec. 2308/2017), y la de contraste la STSJ País Vasco de 11 de octubre de 2016 (Rec. 1821/2016). El TS casa y anula la sentencia recurrida, y confirma la de instancia, que reconoció a la demandante el derecho a la jubilación anticipada.

30 Admite el Alto Tribunal que el criterio hermenéutico plasmado en el art. 4 de la LOIMH ha sido incorporado a otras sentencias de la Sala Cuarta, como: «Sentencia de 21 de diciembre de 2009, recurso 201/2009, en la que a una trabajadora del RETA, se le computó como cotizados, asimilados por parto, los 112 días de bonificación establecidos en la Disposición Adicional Cuadragésimo Cuarta (DA 44.a) de la Ley General de la Seguridad Social (LGSS); sentencia de 26 de enero de 2011, recurso 4587/2009, concediendo pensión de viudedad a mujer divorciada, sin pensión compensatoria, víctima de violencia de género y sentencia de 13 de noviembre de 2019, recurso 75/2018, reconociendo el derecho de los trabajadores puestos a disposición por una ETT a que se les apliquen las medidas contenidas en el plan de igualdad de la empresa usuaria». 
siduales, especialmente en el caso de las mujeres (Flor, 2016: 114). Llama, por ello, la atención la incorporación, como causa de la jubilación anticipada involuntaria, la extinción de la relación laboral de la mujer trabajadora como consecuencia de ser víctima de la violencia de género, sin que, a este colectivo especialmente sensible, se le exonere — al menos parcialmente- del cumplimiento de los exigentes requisitos de acceso arriba señalados.

La falta de perspectiva de género también se aprecia en la anticipación de la edad de jubilación, mediante Decreto y a propuesta del Ministerio de Trabajo, prevista en el art. 206 LGSS para grupos o actividades profesionales cuyos trabajos sean de naturaleza excepcionalmente penosa, tóxica, peligrosa o insalubre y acusen elevados índices de morbilidad o mortalidad. Resulta reprochable la masculinización de los sectores que actualmente se benefician de la jubilación a una edad reducida, entre los que se encuentran, sin ánimo exhaustivo, la minería, el trabajo en el mar, la actividad taurina o el trabajo ferroviario (Ballester, 2011: 74; Flor, 2016: 116-117), obviándose trabajos feminizados como los desarrollados por camareras de piso, trabajadoras al servicio del hogar familiar o cuidadoras profesionales de dependientes, sometidos todos ellos a elevados riesgos físicos derivados del sobreesfuerzo y, en ocasiones, a riesgos de carácter psicosocial y, en consecuencia, con altos índices de morbilidad.

En lo que se refiere al envejecimiento activo, son diversas las fórmulas que actualmente permiten compatibilizar el trabajo y la pensión de jubilación (Cavas, 2017: 75): jubilación flexible y parcial, con reducción proporcional de la pensión (arts. 213.1 y 215.3 LGSS); compatibilidad de la pensión, sin merma de su cuantía, con un trabajo autónomo que genere unos ingresos inferiores al importe del SMI (art. 213.4 LGSS); compatibilidad con el trabajo por cuenta ajena o por cuenta propia - a tiempo completo o parcial - con percibo del $50 \%$ de la pensión mientras se mantenga la compatibilidad, siempre que la pensión se cause a partir de la edad ordinaria de jubilación y con un período cotizado que de derecho al $100 \%$ de la base reguladora —en el supuesto anterior, la pensión se percibe íntegra si el trabajo realizado es por cuenta propia y se tiene a una persona contratada - (art. 214 LGSS).

Las previsiones normativas citadas, pese a sus loables objetivos de fomentar el envejecimiento activo y de garantizar el sostenimiento del sistema - conforme al patrón diseñado por la Unión Europea-, plantean muchos interrogantes, sobre todo, en un contexto de crisis económica no del todo superada - y ahora agravada por la crisis desencadenada por el COVID 19-, con un nivel de desempleo alto, especialmente en el caso de mujeres y jóvenes. Resulta, ciertamente, sorprendente que se aspire a promover la compatibilidad de trabajo y pensión, pese a la dramática situación de desempleo juvenil —situado en el 30,5\% en el último trimestre de 2019, según datos del INE-y la constatada dificultad de las personas mayores — quienes suelen ser utilizadas 
como elementos de ajuste de las plantillas — para llegar a la edad legal de jubilación ${ }^{31}$.

El envejecimiento activo es adecuado para trabajos de carácter intelectual, puestos cualificados y/o de carácter directivo. No son estas las características que presentan profesiones feminizadas relacionadas con la limpieza o los cuidados, de carácter penoso, ni en general, las actividades de baja cualificación que muchas mujeres realizan en el sector servicios; en estos casos, de prolongarse la actividad laboral más allá de la edad ordinaria de jubilación, será por la necesidad de acreditar una carencia que todavía no se ha logrado, o de mejorar la cuantía de la pensión de jubilación. Ni que decir tiene que la fórmula de compatibilidad entre el trabajo y el $50 \%$ de la pensión estará vedada a muchas mujeres que no puedan acreditar una larga carrera de cotización.

\subsection{Modificaciones restrictivas de las reglas de cálculo de la cuantía y pensiones de jubilación de las mujeres}

Las leyes 27/2011, de 1 de agosto, y 23/2013, de 23 de diciembre, han introducido relevantes cambios en las reglas de cálculo de la cuantía de la pensión de jubilación, dirigidas a reducir su importe, que, una vez más, inciden de forma negativa en las pensiones de jubilación de las mujeres. Dichos cambios han endurecido las reglas de cálculo de la base reguladora, y han supuesto la creación del factor de sostenibilidad y del Índice de Revalorización del Sistema de Pensiones (IRP).

Las nuevas reglas de cálculo de la base reguladora de la pensión de jubilación han determinado que se tengan en cuenta las bases de cotización de los 300 meses inmediatamente anteriores al mes previo al del hecho causante (art. 209 LGSS) ${ }^{32}$, medida que se aplicará íntegramente cuando finalice su período transitorio en 2022. Son 25 años de cotización continuada (con anterioridad eran 15) que serán más difíciles de acreditar por parte de las mujeres, con carreras intermitentes y numerosas lagunas de cotización, por la asunción del rol de cuidados durante ese período, y, en ocasiones, por el desarrollo de trabajos en el ámbito de la economía informal.

En el caso de existencia de lagunas de cotización en el período que haya de tomarse para el cálculo de la base reguladora, las primeras cuarenta y ocho mensualidades se integrarán con la base mínima de cada momento, y el resto de mensualidades con el $50 \%$ de dicha base mínima (art. 209.1.b LGSS), lo que mermará sensiblemente dicha base reguladora.

31 Téngase en cuenta que, según se reconoce en el Libro Verde de la Comisión Europea, cit., en Europa menos del $50 \%$ de la población sigue trabajando a la edad de sesenta ańos.

32 Reforma llevada a efecto por Ley 27/2011, de 1 de agosto, sobre actualización, adecuación y modernización del sistema de Seguridad Social. 
Ahora bien, esta solución, no siendo óptima, siempre será mejor que la aplicable a las trabajadoras del RETA y del sistema especial de personas empleadas de hogar, a las que, injustificadamente, no se les extiende esta norma (arts. 318.d) y 256.7 LGSS), lo que contribuye a empeorar unas pensiones, ya de por sí mermadas, en ambos colectivos. Así, en el RETA, en marzo de 2020 la pensión de jubilación media femenina fue de 643,40 euros, frente a la masculina de 867,85 euros $^{33}$; por su parte en el sistema especial de personas empleadas de hogar (casi totalmente feminizado), la pensión media se sitúa en torno a los 500 euros (Sanz, 2018: 89).

Otra medida restrictiva adoptada ha sido el incremento gradual del número de años cotizados que se exigen para tener derecho al $100 \%$ de la base reguladora (art. 210 LGSS) ${ }^{34}$, que, a la finalización del período transitorio establecido por la Disposición Transitoria 9. ${ }^{a}$ LGSS (2027), será de 37 años. Sin duda, pocas mujeres, de mantenerse las circunstancias actuales, podrán percibir una pensión equivalente al $100 \%$ de su base reguladora, pues, si bien la duración media de la vida laboral de las mismas es cada vez mayor, habiendo pasado de 24,2 años en el 2000, a 32,8 años en 2017, todavía están lejos de los 37 años exigidos. Menos dificultades, a tales efectos, tendrán los hombres, teniendo en cuenta que su promedio de ańos cotizado se viene manteniendo estable desde el año 2000, precisamente, en 37 años $^{35}$. Legislar sin perspectiva de género y tomando como referente al varón con largas carreras de cotización, permite que se produzcan efectos como el descrito, generadores de discriminación indirecta por razón de sexo, al impedir a más mujeres que hombres alcanzar el 100\% de la base reguladora de la pensión de jubilación.

El factor de sostenibilidad también es susceptible de contribuir a mermar las ya exiguas pensiones femeninas ${ }^{36}$. Dicho factor es un instrumento automático que tiene como objeto ajustar las cuantías de las pensiones de jubilación en el momento de su cálculo, con la finalidad de que el importe total que perciba quien, en un momento determinado, acceda al sistema de pensiones, sea equivalente al que perciba quien se jubile con posterioridad teniendo una mayor esperanza de vida. Su aplicación estaba prevista a las pensiones causadas a partir del 1 de enero de 2019; sin embargo, la LPGE 2018, dando respuesta al clamor social contrario al factor de sostenibilidad, ha retrasado su aplicación hasta que la

33 http://www.seg-social.es/wps/wcm/connect/wss/9d655ebf-e510-4d58-abcf-6add02e4b99a/ REG3202003.pdf?MOD=AJPERES\&CONVERT_TO=linktext $\&$ ContentCache=NONE\&CAC HE=NONE\&CACHEID=ROOTWORKSPACE.Z18_9H5AH880M8TN80QOV0H20V00009d655ebf-e510-4d58-abcf-6add02e4b99a-n4JYDZ2 (accedido: 8-04-2020).

34 Medida materializada por la Ley 27/2011.

35 Véase, ClosinGap, Women for a Healthy Economy: Coste de oportunidad de la brecha de género en las pensiones, Informe 3, abril, 2019, p. 28.

36 Medida incorporada por la Ley 23/2013, de 23 de diciembre, reguladora del Factor de Sostenibilidad y del Índice de Revalorización del Sistema de Pensiones de la Seguridad Social. 
Comisión del Pacto de Toledo alcance un acuerdo sobre la aplicación de las medidas necesarias para garantizar la sostenibilidad del sistema, y en todo caso, a una fecha no posterior al 1 de enero de 2023. Sin duda, la demora en la aplicación de la medida a la espera de que se adopte un acuerdo es una buena noticia, pero no resulta suficiente. La Comisión del Pacto de Toledo también deberá velar por que las medidas que se adopten para lograr la sostenibilidad del sistema no contribuyan a aumentar la brecha de género de la pensión de jubilación.

Por su parte, el Índice de Revalorización del Sistema de Pensiones (IRP) ${ }^{37}$, establecido en el art. 58 LGSS, vino a sustituir al IPC registrado en el mes de noviembre anterior. De acuerdo con la citada norma, las pensiones de la Seguridad Social en su modalidad contributiva se incrementarán al comienzo de cada año en función del IRP previsto en la correspondiente LPGE. El IRP se calcula con arreglo a una fórmula matemática que pondera diversos factores relacionados con la situación de las cuentas de la Seguridad Social (relación entre ingresos y gastos, efecto sustitución...), no pudiendo resultar un incremento anual inferior al 0,25\%, ni superior a la variación del IPC en el periodo anual anterior a diciembre del año de referencia más un $0,50 \%$. En la práctica, se ha aplicado el incremento anual mínimo del 0,25\%, generando un estancamiento de las pensiones que, una vez más, ha perjudicado de manera especial a las mujeres. Sin que se haya modificado el art. 58 LGSS, el IRP no se ha aplicado de facto en 2018, ni en 2019, ni en 2020, sino una fórmula de revalorización directamente ligada al IPC, que, todo parece indicar, se mantendrá en el futuro; esta medida, contemplada en la LPGE 2018, y prorrogada para 2019 y 2020, unida al incremento de las pensiones mínimas en un 3\% en 2019 y un 0,9\% en 2020) han contribuido a mejorar la cuantía de las pensiones de jubilación femeninas.

\subsection{El impacto de género del recorte de la cuantía del complemento por mínimos}

Conforme al art. 59 LGSS, para tener derecho al complemento por mínimos es preciso no alcanzar la cuantía mínima prevista cada año para la pensión contributiva de que se trate, demostrar carencia de rentas (no percibir rendimientos del trabajo, del capital o de actividades económicas y ganancias patrimoniales, de acuerdo con el concepto establecido para dichas rentas en el IRPF, o que, percibiéndolos, no excedan de la cuantía que anualmente establezca la correspondiente LPGE), y residir en territorio español.

Debido a la brecha salarial, la alta incidencia del trabajo a tiempo parcial, las intermitentes carreras de cotización, y al impacto de género de las últimas reformas, muchas pensiones de jubilación femenina no lograrán alcanzar la cuantía mínima y habrán de ser complementadas. Es significativo que, a principios del

${ }^{37}$ Medida introducida por la Ley 23/2013, de 23 de diciembre. 
año 2020, el 30\% de las pensiones disfrutadas por las mujeres necesiten complemento a mínimos, frente al $17 \%$ de las pensiones masculinas ${ }^{38}$. Estas cifras evidencian que el complemento a mínimos puede contribuir a dignificar la cuantía de las pensiones femeninas y garantizar su suficiencia con bastante eficacia ${ }^{39}$, función, que tras la reforma de las pensiones de 2011 se ha visto devaluada.

La Ley 27/2011 modificó el régimen jurídico de los complementos para pensiones inferiores a la mínima, introduciendo elementos propios de las pensiones no contributivas (Errandonea, 2015: 78). El contenido de dicha reforma se contiene hoy en el art. 59.2 LGSS, donde se prevé que el complemento por mínimos no podrá, en ningún caso, «superar la cuantía establecida en cada ejercicio para las pensiones no contributivas de jubilación e invalidez».

La reforma, que refuerza la contributividad del sistema y limita el principio de solidaridad, constituye un ataque frontal a la garantía de suficiencia de las pensiones exigida por la CE (arts. 41 y 50), pues permitirá que personas que tengan derecho al complemento no alcancen la pensión de mínima establecida en la LPGE de cada ańo. La reforma genera un evidente impacto negativo de género, al ser las mujeres quienes perciben mayoritariamente dichos complementos.

\section{Discriminación por razón de sexo en el régimen jurídico de la pensión de jubilación y doctrina del TJUE}

\subsection{La insatisfactoria regulación de la pensión de jubilación en el trabajo a tiempo parcial}

\section{a) Una tortuosa evolución normativa}

Como se ha señalado, el $74 \%$ del total del trabajo a tiempo parcial lo desempeñan trabajadoras, configurándose de facto esta modalidad contractual como un instrumento de conciliación familiar y laboral feminizado, a resultas de la asunción por aquellas del rol social de cuidados. La ocupación de trabajos a tiempo parcial por parte de las mujeres, en un porcentaje tan elevado, es uno de los factores determinantes de la menor cuantía de las pensiones femeninas, dado que, por lo pronto, tales trabajos generan salarios bajos y menguadas cotizaciones. Siendo así, el diseño del sistema de la protección social de esta modalidad contractual no resultará neutro, sino que impactará positiva o negativamente en el nivel de tutela que nuestro sistema de Seguridad Social dispense a las mujeres.

\footnotetext{
38 https://revista.seg-social.es/2020/03/06/la-mujer-en-la-seguridad-social-breve-radiografia-desituacion/ (accedido: 27-3-2020).

39 Y todo ello a pesar de que, paradójicamente, los hombres reciban complementos a mínimos más altos, por ser su cuantía más elevada cuando existe cónyuge a cargo.
} 
La regulación de la protección social del trabajo a tiempo parcial ha tenido una evolución tortuosa desde la década de los setenta del pasado siglo hasta la actualidad, sin que se haya escrito todavía el último capítulo en la materia. En los años setenta, el menor salario derivado de la jornada reducida no incidía en la cotización, ni en el nivel de protección, al cotizarse por bases tarifadas independientes de la retribución. Es el Estatuto de los Trabajadores de 1980 el que, con el objetivo de fomentar esta modalidad contractual reduciendo sus costes, establece el criterio de proporcionalidad puro, habiéndose de efectuar la cotización por los días u horas realmente trabajados. Criterio de proporcionalidad que, con algunos vaivenes, acaba trasladándose a la protección social, señalando la Disposición adicional 7. ${ }^{\text {a }}$ LGSS 1994 que, a efectos de determinar los periodos de cotización y la base reguladora de las prestaciones, se computarían exclusivamente las horas trabajadas. En lo que se refiere al cálculo de la carencia, este sistema fue declarado inconstitucional por la STC 253/2004, de 22 de diciembre; el TC consideró que dicho sistema, al exigir períodos mínimos de cotización más amplios, dificultaba, especialmente a las mujeres, el acceso a la protección social, generando discriminación indirecta por razón de sexo.

La sentencia tuvo escaso impacto dado que el sistema ya había sido modificado por el Real Decreto-Ley 15/1998, que reformó la Disposición adicional 7. ${ }^{\text {a }}$ LGSS 1994. La nueva norma mantuvo el criterio de la proporcionalidad, pero introdujo correcciones tanto en materia de carencia como en cuanto al cálculo de la cuantía. Por lo pronto, para acreditar la carencia se computarían las cotizaciones en función de las horas trabajadas, calculando su equivalencia en días teóricos de cotización, para lo cual era preciso dividir entre 5 el total de horas efectivamente trabajadas; al cociente así obtenido se le aplicaría el coeficiente multiplicador de 1,5 - factor de corrección- para calcular el total de años cotizados. La base reguladora se calcularía conforme a las reglas generales; y el porcentaje aplicable a la misma vendría determinado por el número de años cotizados, calculados, conforme a la regla señalada.

El sistema de cómputo del período mínimo de cotización establecido en la Disposición adicional 7. ${ }^{a}$ LGSS 1994 fue declarado contrario al Derecho de la Unión Europea por la STJUE de 22 de noviembre de 2012, Caso Elbal Moreno (C-385/11), al incurrir en discriminación indirecta por razón de sexo. El TSJUE interpretó que el criterio inducía a una doble penalización a quienes trabajan a tiempo parcial, mayoritariamente mujeres: la exigencia de un mayor período de cotización, que se añade a la obtención de unas pensiones, razonablemente más reducidas a consecuencia de salarios y cotizaciones menores. Apenas cuatro meses después, la STC 61/2013, de 13 de marzo, siguiendo la línea marcada por el TJUE, declara inconstitucional la medida por vulnerar el principio de igualdad y generar discriminación indirecta por razón de sexo. 
Tras la STC 61/2013, el Real Decreto-Ley 11/2013, de 2 de agosto, y la Ley $1 / 2014$, de 28 de febrero, modifican la regulación de la materia, mediante el diseño de una compleja fórmula hoy contenida en los arts. 245 y ss. LGSS (y nuevamente puesta en cuestión). De tal manera que, para la determinación de la carencia, se calculan los períodos en los que la persona trabajadora ha prestado servicios con un contrato a tiempo parcial, y a continuación se determina el "coeficiente de parcialidad» (porcentaje de la jornada realizada a tiempo parcial respecto de la llevada a efecto por una persona trabajadora a tiempo completo comparable); el coeficiente se aplica sobre el tiempo en que se ha estado trabajando a tiempo parcial, para obtener el número de días que se consideran efectivamente cotizados. A este número de días se le suman los días cotizados a tiempo completo, a efectos de carencia. A continuación, se calcula el "coeficiente global de parcialidad", que es el porcentaje que representa el número de días trabajados y acreditados, conforme a la regla anterior, sobre el total de días en alta de la persona trabajadora. El período mínimo de cotización exigido, será el resultado de aplicar al período regulado con carácter general el coeficiente global de parcialidad. De este modo, la nueva fórmula adapta el período de carencia exigido al promedio de trabajo a tiempo parcial realizado por la persona trabajadora a lo largo de su vida laboral (Desdentado, 2019: 108).

En lo referente al cálculo de la cuantía de las pensiones de jubilación y de incapacidad permanente derivada de enfermedad común, el número de días cotizados que resulten de lo establecido para calcular la carencia, se incrementará con la aplicación del coeficiente del 1,5, sin que el número de días resultante pueda ser superior al período de alta a tiempo parcial. El porcentaje aplicable a la base reguladora se determinará conforme a la escala general, con una medida correctora aplicable a quienes acrediten un período de cotización inferior a quince ańos (con el incremento del coeficiente del 1,5); en este caso, «el porcentaje a aplicar sobre la respectiva base reguladora será el equivalente al que resulte de aplicar a 50 el porcentaje que represente el período de cotización acreditado por el trabajador sobre quince años ${ }^{40}$. El nuevo sistema facilita el acceso a la pensión de jubilación en el trabajo a tiempo parcial, al flexibilizar el requisito de carencia, pero asegura bajos importes, tanto por las reducidas bases de cotización acreditadas como por el sistema de cálculo de la cuantía (Cabeza, 2014: 2); por ello, estas pensiones, disfrutadas mayoritariamente por mujeres, son complementadas por mínimos (Espín, 2016: 23; Desdentado, 2019: 109). Una vez más, se evidencia el relevante papel que tales complementos puede desempeñar para garantizar la suficiencia de un alto número de pensiones femeninas.

${ }^{40}$ Art. 248.3, último párrafo, LGSS. 


\section{b) Las sentencias TJUE de 8 de mayo de 2019 y TC 91/2019 de 3 de julio}

Cuando pudiera parecer que la regulación de la materia había quedaba definitivamente zanjada, la STJUE de 8 de mayo de 2019 (Asunto Villar Láiz, C-161/18) volvió a plantear objeciones a la regulación de la materia, nuevamente, por no incorporar en su diseño una perspectiva de género, y por falta de proporcionalidad de las reglas de cálculo de la cuantía al reducir el importe de la pensión en una proporción mayor a la correspondiente a los períodos de ocupación a tiempo parcial.

En particular, el Tribunal de Luxemburgo ha resuelto que el art. 4.1 de la Directiva 79/7/CEE del Consejo, de 19 de diciembre de 1978, ha de interpretarse en el sentido de que tal Directiva se opone a una normativa de un Estado miembro, como la controvertida, según la cual el importe de la pensión de jubilación contributiva de una persona trabajadora a tiempo parcial se calcula multiplicando una base reguladora, determinada en función de los salarios y las cotizaciones correspondientes, por un porcentaje que depende de la duración del período de cotización - período al que se aplica un coeficiente de parcialidad equivalente a la relación existente entre la jornada a tiempo parcial efectivamente trabajada y la jornada realizada por un trabajador a tiempo completo comparable y que se ve incrementado por un coeficiente de 1,5-, en la medida en que esta normativa perjudique en particular a las trabajadoras respecto de los trabajadores.

Y, una vez más, la STJUE es seguida — con apenas dos meses de separación temporal- por la STC de 3 de julio de 2019. En esta resolución, el Alto Tribunal declara que es inconstitucional, nula y discriminatoria para las mujeres la diferencia existente, en el sistema de cálculo de la pensión de jubilación, para quienes trabajan a tiempo completo y parcial, al carecer de justificación objetiva y razonable. En la misma línea señalada por el TJUE, para el TC, «lo que no resulta justificado» es que se establezca una diferencia de trato entre ambos colectivos «no ya en cuanto a la reducción de la base reguladora para el trabajador a tiempo parcial en función de su menor base de cotización, sino en cuanto a la reducción adicional de la base reguladora mediante un porcentaje derivado de un coeficiente de parcialidad que reduce el número efectivo de días cotizados». A juicio del TC, esa diferenciación no sólo conduce a un resultado perjudicial en el disfrute de la protección de la Seguridad Social para quienes trabajan a tiempo parcial, lo que vulnera el principio de igualdad ante la ley, «sino que afecta predominantemente a las mujeres trabajadoras, como revelan los datos estadísticos», lo que es constitutivo de discriminación indirecta por razón de sexo.

En tanto se produce la adaptación legislativa correspondiente, el Criterio de Gestión 17/2019 de la Subdirección General de Ordenación y Asistencia Jurídica del INSS, de 12 de agosto de 2019, partiendo de que la STC 91/2019 ha declarado la inconstitucionalidad y nulidad del inciso "de jubilación y» del apar- 
tado 3 del art. 248 LGSS, ha establecido el siguiente criterio interpretativo provisional para la aplicación de la sentencia por parte de la entidad gestora:

1. La sentencia del TC incide únicamente en la determinación del porcentaje aplicable a la base reguladora para el cálculo de la cuantía de la pensión de jubilación, no afectando al cálculo de la base reguladora de la pensión de incapacidad permanente derivada de enfermedad común.

2. La aplicación de la sentencia del TC conlleva que en aquellos supuestos en los que la persona trabajadora haya desempeńado trabajos a tiempo parcial, para la determinación del porcentaje aplicable a la base reguladora de la pensión de jubilación se tomen en consideración los periodos en los que aquella hubiera permanecido en alta con un contrato a tiempo parcial, cualquiera que sea la duración de la jornada. Así pues, no se aplicará el coeficiente de parcialidad, debiendo calcularse la cuantía de la pensión de jubilación de acuerdo con el porcentaje que resulte conforme a la regla general.

3. La sentencia del TC surte efectos a partir del 12 de agosto de 2019 , fecha de su publicación en el BOE. Queda preservada la cosa juzgada, así como las situaciones administrativas firmes.

\subsection{El complemento por maternidad de las pensiones contributivas}

\section{a) Análisis crítico del art. 60 LGSS}

Establece el art. 60 LGSS — tras la reforma llevada a efecto por la Ley 48/2015, de 29 de octubre-, con efectos del 1 de enero de $2016^{41}$, que «las mujeres que hayan tenido hijos biológicos o adoptados y sean beneficiarias en cualquier régimen del sistema de la Seguridad Social de pensiones contributivas de jubilación, viudedad o incapacidad permanente», tendrán derecho a un complemento de pensión "por su aportación demográfica a la Seguridad Social», que se condiciona al cumplimiento de dos requisitos:

En primer lugar, ha de tratarse de madres que hayan tenido, al menos, dos hijos/as por naturaleza o adopción — queda excluido el acogimiento- antes del hecho causante de la prestación, lo que deja fuera del beneficio a los padres, así como a las madres con una sola hija o hijo, pese a que estas también han contribuido «demográficamente» al sostenimiento del sistema. No señala la norma

41 El Juzgado de lo Social no 26 de Barcelona (España) ha planteado Petición de decisión prejudicial el 26 de noviembre de 2019 [LJ/INSS (Instituto Nacional de la Seguridad Social)-(Asunto C-861/19)], sobre si se puede considerar que el complemento de maternidad una medida o acción positiva dirigida a lograr la igualdad material entre mujeres y hombres al amparo del art. 157.4 del Tratado de Funcionamiento de la Unión Europea, y en caso de respuesta positiva a la anterior cuestión, si se opone al principio de proporcionalidad al que debe someterse toda acción positiva la limitación temporal a las pensiones causadas a partir del 1 de enero de 2016. 
que la criatura haya de nacer viva. Pese a ello, la STSJ Canarias/Las Palmas de 11 de septiembre 2019 (Rec. 1311/2018, Ponente: Ignacio Duce Sánchez de Moya) así lo interpreta, en el entendimiento de que la finalidad de la previsión es el «sostenimiento del propio sistema de Seguridad Social y su viabilidad, mediante el nacimiento, cuidado, mantenimiento y educación de los hijos —nacidos o adoptivos - como hipotéticos y futuros integrantes del mismo». La resolución incluye un lúcido voto particular a cargo de la Magistrada Gloria Poyatos Matas - al que se adhiere la Magistrada Marina Mas Carrillo_-, en el que se advierte que la norma, que tiene por finalidad compensar los históricos efectos negativos de la maternidad biológica — que incluye el embarazo, el parto, y el puerperio - en materia de Seguridad Social, no exige que la criatura haya nacido viva ni que haya vivido un tiempo determinado tras el parto, pues tal exigencia supondría «cosificar a las mujeres y protegerlas condicionalmente solo en los casos en los que produzcan hijos/as vivos/as».

$Y$, en segundo término, se exige que la mujer sea beneficiaria, en cualquier régimen del sistema, de pensiones contributivas de jubilación, viudedad o incapacidad permanente. Se excluye del complemento la jubilación anticipada voluntaria - lo que ha sido considerado conforme a la CE por el $\mathrm{TC}^{42}$ - y la jubilación parcial, si bien, en este segundo caso, se asignará el complemento cuando se acceda a la jubilación plena. Asimismo, quedan fuera del beneficio las pensiones no contributivas.

El complemento por maternidad, al que se le reconoce la naturaleza jurídica de pensión pública contributiva, consiste en un importe equivalente al resultado de aplicar a la cuantía inicial de la pensión un porcentaje determinado, en función del número de criaturas, según la siguiente escala: a) en el caso de dos hijos/as, un 5\%; b) en el caso de tres, un 10\%; y c) en el caso de cuatro o más, un $15 \%$.

Dicho importe, que constituye la regla general, cuenta con tres excepciones: 1) Si a la trabajadora se le reconoce el derecho a percibir la pensión máxima antes de aplicar el complemento, percibirá la mitad de este; y, de alcanzar el importe de la pensión máxima aplicando únicamente parte del complemento, tendrá derecho a percibir el $50 \%$ de la parte del complemento que exceda del límite máximo vigente en cada momento. 2) En el caso de que la pensión no alcance la cuantía mínima, la misma se complementará conforme a lo establecido en el art. 59 LGSS, y sobre ese importe se aplicará el complemento por maternidad cuya cuantía será el resultado de aplicar el porcentaje que corresponda a la pensión inicialmente calculada. 3) Y, finalmente, en el supuesto de concurrencia de pensiones del sistema de la Seguridad Social, se reconocerá el complemento

42 Véase, Auto del Pleno del TC, N.o 114/2018, de 16 de octubre de 2018 (Cuestión de inconstitucionalidad 3307/2018). 
por maternidad solamente a una de las pensiones de la beneficiaria, de acuerdo con el siguiente orden de preferencia: $10^{\circ}$ La pensión que resulte más favorable. 2. ${ }^{\circ}$ Si concurre una pensión de jubilación con una pensión de viudedad, el complemento se aplicará a la de jubilación.

De la regulación expuesta se infiere que el complemento por maternidad constituye, como regla general, un reconocimiento a las mujeres trabajadoras que han compatibilizado su carrera laboral con la maternidad, "por su contribución demográfica» y siempre que, al menos, hayan tenido dos hijos/as. Se obvia, en todo caso, a las que sólo han tenido una criatura, en muchos casos forzadas por la situación económica familiar; así como a las que se vieron en la necesidad de abandonar sus trabajos para desarrollar en exclusiva el rol de cuidadoras - coincidentes, normalmente, con aquellas que no pudieron contratar servicios de cuidados externos por sus bajos salarios-, y no han tenido acceso a una pensión contributiva de jubilación por falta de carencia. Paradójicamente, sí se aplica el complemento a la pensión de viudedad que, si bien tiene carácter contributivo, no está vinculada al trabajo previo de la beneficiaria.

La medida es cuestionable pues, lejos de promover la igualdad y la corresponsabilidad entre ambos sexos - en la línea marcada por la normativa interna, internacional y de la Unión Europea-, supone un retroceso al asignar a las mujeres el rol de cuidadoras (Flor, 2016:124), premiándolas sólo a ellas por razón del nacimiento y el cuidado de menores, con exclusión de los padres. Además, la previsión entra en contradicción con el nuevo permiso por nacimiento y cuidado de menor (art. 48.4 ET), que reconoce permisos iguales - de 16 semanas- e intransferibles a ambos progenitores, con la finalidad de impulsar la corresponsabilidad y superar el rol de género de cuidados. Y, en fin, la norma no garantiza que las mujeres que tuvieron que renunciar a sus trabajos para cuidar a sus hijos/s se beneficien de la medida (de hecho, no alcanza a beneficiarias de pensiones no contributivas), ni impide que tengan derecho a la misma aquellas mujeres que no vieron afectadas sus carreras de cotización por la crianza de sus hijos/as alcanzando las pensiones máximas.

De otro lado, la regulación del art. 60 LGSS no se aviene bien con la normativa de la Unión Europea, a la vista de algunos pronunciamientos del TJUE, como la sentencia de 29 de noviembre de 2001 (asunto C-366/99, Griesmar) que, en relación con el régimen francés de jubilación de personal funcionario que reconocía determinados beneficios sólo a las funcionarias por cada hijo/a, consideró que el mismo vulneraba el principio de igualdad de retribución al excluir de la bonificación establecida para el cálculo de las pensiones de jubilación a los funcionarios que podían probar haber asumido el cuidado de sus hijos/as. Y, asimismo, no resulta coherente con el tenor de la STJUE de 30 de septiembre de 2010 (asunto 104/09, Roca Álvarez), que integra el principio de correspon- 
sabilidad como criterio de interpretación en la adecuación de la normativa espańola al Derecho de la Unión Europea, respecto del permiso de lactancia; ni con el de la STJUE de 16 de julio de 2015 (asunto C-222/2014, Maïstrellis), que señala que un permiso parental condicionado, en el caso del padre, a que la madre trabaje puede contribuir a perpetuar un reparto roles entre hombres y mujeres al mantener a los hombres en una función subsidiaria de las mujeres respecto al ejercicio de su función parental.

\section{b) La STJUE de 12 de diciembre de 2019}

A la vista de las dudas suscitadas por el art. 60 LGSS respecto de su conformidad con la normativa de la Unión Europea, algunos órganos judiciales elevaron cuestiones prejudiciales al TJUE. Así, el Tribunal Superior de Justicia de Canarias, en Auto de 7 de diciembre de 2018 -Ponente: Gloria Poyatos Matas_ ${ }^{43}$, planteó al Tribunal de Luxemburgo si el complemento de maternidad, del que se excluye de forma absoluta e incondicional a los padres pensionistas que puedan probar haber asumido el cuidado de sus hijos/as, es contrario al art. 157 TFUE y al art. 4.1. de la Directiva 79/77CEE del Consejo, de 19 de diciembre de 1978, relativa a la aplicación progresiva del principio de igualdad de trato entre hombres y mujeres en materia de Seguridad Social. Pocos meses antes, el Juzgado de lo Social núm. 3 de Girona, mediante Auto de 21 de junio de 2018, había planteado una cuestión de prejudicial, en similares términos, en relación con un conflicto suscitado entre un pensionista de incapacidad permanente absoluta que reclamaba el complemento por maternidad y el INSS que había rechazado tal reclamación.

Es a la cuestión prejudicial planteada por el Juzgado de lo Social de Girona a la que da respuesta la STJUE de 12 de diciembre de 2019 (C-450/18 WA/ Instituto Nacional de la Seguridad Social). El Tribunal de Justicia declara que la Directiva 79/7/CEE del Consejo, de 19 de diciembre de 1978, relativa a la aplicación progresiva del principio de igualdad de trato entre hombres y mujeres en materia de Seguridad Social se opone a la norma española, ya que los hombres que se encuentren en una situación idéntica a la de las mujeres que perciben el complemento de pensión no tienen derecho al mismo. A juicio del Tribunal de Luxemburgo, la norma espańola concede un trato menos favorable a los hombres que hayan tenido al menos dos hijos/as biológicos/as o adoptados/as, trato desfavorable que es constitutivo de discriminación directa por razón de sexo, prohibida por la Directiva.

A este respecto, razona el TJUE que, en la medida en que la aportación demográfica a la Seguridad Social de los hombres es tan necesaria como la de las mujeres, esta circunstancia no puede justificar por sí sola que los hombres y las

${ }^{43}$ Rec. 850/2018. 
mujeres no se encuentren en una situación comparable en lo que respecta a la concesión del complemento de pensión regulado en el art. 60 LGSS.

Las autoridades españolas aducen que el complemento fue concebido también como una medida destinada a reducir la brecha de género existente entre las pensiones de los hombres y las de las mujeres cuyas carreras profesionales se hayan visto interrumpidas o acortadas por haber tenido al menos dos criaturas, diferencias que se desprenden de numerosos datos estadísticos. En lo que se refiere a este objetivo, el TJUE admite que la norma espańola tiene por objeto, al menos parcialmente, la protección de las mujeres en su condición de progenitoras; sin embargo — razona_, por un lado, se trata de una cualidad predicable tanto de hombres como de mujeres y, por otro, las situaciones de un padre y una madre pueden ser comparables en cuanto al cuidado de su prole. En este contexto, la existencia de datos estadísticos que muestren diferencias estructurales entre los importes de las pensiones de las mujeres y de los hombres no sería suficiente para llegar a la conclusión de que las mujeres y los hombres no se encuentran en una situación comparable en su condición de progenitores en relación con el denominado complemento de maternidad.

Según el TJUE, habida cuenta de las características del complemento por maternidad, este no está incluido en los supuestos en los que cabe una excepción a la prohibición de toda discriminación directa por razón de sexo previstos por la Directiva, en su art. 4.2. Y, es que, en primer lugar, en lo tocante a la excepción relativa a la protección de la mujer por motivos de maternidad, la norma española no contiene ningún elemento que establezca un vínculo entre la concesión del complemento y el disfrute de un permiso de maternidad o las desventajas que sufre una mujer en su carrera debido a la interrupción de su actividad durante el período que sigue al parto. Y, en segundo término, por lo que respecta a la excepción que permite a los Estados miembros excluir del ámbito de aplicación de la Directiva las ventajas concedidas en materia de seguro de vejez a las personas que han educado hijos/as y la adquisición del derecho a las prestaciones después de períodos de interrupción de empleo debidos a su educación, el TJUE pone de manifiesto que la norma española no supedita la concesión del complemento por maternidad a la educación de los/as hijos/as o a la existencia de períodos de interrupción de empleo debidos a la educación de los/as mismos/ as, sino únicamente a haber tenido al menos dos hijos/as biológicos/as o adoptados/os y al hecho de percibir una pensión contributiva.

Por último, el complemento controvertido tampoco está incluido en el ámbito de aplicación del art. 157 TFUE, apartado 4, el cual, con objeto de garantizar en la práctica la plena igualdad entre hombres y mujeres en la vida laboral, permite a los Estados miembros mantener o adoptar medidas que ofrezcan ventajas concretas destinadas a facilitar al sexo menos representado el ejercicio de actividades profesionales o a evitar o compensar desventajas en sus carreras pro- 
fesionales. Ciertamente, el denominado complemento por maternidad se limita a conceder a las mujeres un plus en el momento del reconocimiento del derecho a una pensión, sin aportar ninguna solución a los problemas a los que puedan tener que hacer frente durante su carrera profesional ni compensar las desventajas a las que puedan verse expuestas.

La STJUE evidencia — una vez más — la falta de adecuación de algunos aspectos de la normativa española de protección social respecto del Derecho antidiscriminatorio de la Unión Europea. Una previsión bienintencionada, basada en la constatación estadística de los efectos de la maternidad y de la asunción por las mujeres del rol de cuidados en la brecha de género en materia de protección social, y que, ciertamente, ha beneficiado a más de 600.000 mujeres pensionistas, ha sido declarada directamente discriminatoria respecto de los hombres por no haber sido diseñada teniendo en cuenta las excepciones a la prohibición de toda discriminación directa por razón de sexo previstas por la Directiva 79/77CEE del Consejo, de 19 de diciembre de 1978, quedando - como resultado - desactivado el efecto perseguido de reducir la brecha entre hombres y mujeres en la cuantía de las pensiones.

El TJUE podría haber dado un paso más para apreciar que la medida también afecta negativamente a las mujeres al fomentar la perpetuación del rol de género de cuidados, que está en la base de la brecha prestacional. La perspectiva de género de la que, en parte, adolece la STJUE sí se observa en la STSJ de Canarias de 20 de enero de 2020 - Ponente: Gloria Poyatos Matas, N.o de Recurso 850/2018 - dictada tras desistir este órgano judicial de la cuestión prejudicial planteada en diciembre de 2018 en relación con un asunto similar, y en la que, en aplicación de la jurisprudencia de la STJUE de 12 de diciembre de 2019, se reconoce el complemento por maternidad a la pensión de jubilación de un padre viudo con cuatro hijos. Señala el TSJ de Canarias que «compensar las desventajas sufridas en el desarrollo de la carrera profesional por las madres trabajadoras, por dedicarse a la crianza de sus hijos/as constituye un objetivo legítimo de política social, pero (...) suscita dudas interpretativas la total e incondicional exclusión de los padres, porque ello puede incentivar el abandono femenino del mercado laboral para el cuidado de hijos/as, fomentando la segregación de roles de género"; razonamiento al que el TSJ de Canarias añade el argumento de que el hecho de que las mujeres estén más afectadas por las desventajas profesionales derivadas del cuidado de los hijos/as porque, en general, asumen esta tarea, «no puede excluir la posibilidad de comparación de su situación con la de un hombre que asuma tales cuidados y que, por esa razón, haya podido sufrir las mismas desventajas en su carrera».

Las consecuencias que se derivarán del tenor de la STJUE todavía son inciertas. Ahora bien, dado que será preciso llevar a cabo una modificación normativa, esta debería incluir; 1) un cambio de denominación de la medida, por 
ejemplo: «complemento por nacimiento y cuidado de menor»; 2) la vinculación de la misma con los perjuicios ocasionados en la carrera de seguro de mujeres y hombres por el disfrute de permisos o excedencias, o la interrupción de la actividad laboral para atender a menores, lo que permitiría que, en la práctica, la medida fuera aplicada fundamentalmente a mujeres - que son las que mayoritariamente sufren lagunas de cotización o bases de cotización reducidas por tales motivos-, pero no impediría que la ventaja también se extendiera a los hombres que se encuentren en iguales circunstancias; 3) el reconocimiento del complemento a partir de la primera criatura (no sólo biológica o adoptada, sino también acogida); 4) la extensión del mismo a quienes no hayan podido acceder a las correspondientes pensiones contributivas por falta de carencia motivada por la dedicación a tales cuidados, y disfruten de una pensión no contributiva.

\section{Breve referencia a las medidas compensatorias}

Para reducir la brecha de género en la pensión de jubilación, se han establecido determinadas medidas correctoras, con efectos dispares. Se trata de acciones positivas que pretenden compensar las consecuencias negativas en las prestaciones sociales del disfrute mayoritariamente femenino de las medidas de conciliación (Martínez, 2017: 18), medidas que será necesario mantener mientras subsista la brecha prestacional, pero que habrá que gestionar con cautela para evitar que contribuyan a perpetuar el reparto de roles tradicionales, como ya se ha comprobado que sucede con el complemento por maternidad. Unas se encaminan a facilitar el cumplimiento del requisito de carencia y a la mejora de la cuantía y otras, específicamente, a incrementar la cuantía.

Entre las medidas que facilitan la carencia y mejoran la cuantía se encuentra, por una parte, el mantenimiento de la obligación de cotizar en determinados supuestos suspensivos del contrato de trabajo (art. 144.4 LGSS): riesgo durante el embarazo, riesgo durante la lactancia natural, descanso por nacimiento, adopción, guarda con fines de adopción y acogimiento e incapacidad temporal. $\mathrm{Y}$, por otra parte, la asimilación de determinados períodos de actividad a cotizados: 1) Los períodos de hasta tres años de excedencia por cuidado de hijo/a o menor tendrán la consideración de periodo de cotización efectiva a efectos de jubilación, incapacidad permanente, muerte y supervivencia, maternidad y paternidad, así como el primer año de excedencia para el cuidado de familiares (art. 237 LGSS). 2) Se reconocen 112 días de cotización asimilados por parto — se excluye la adopción y el acogimiento- y 14 días por cada hijo/a adicional, siempre que la beneficiaria — quedan excluidos los padres - no haya cotizado durante la totalidad de las dieciséis semanas de descanso o el tiempo que corresponda, desde una situación de actividad por cuenta ajena o propia (art. 235 
LGSS). 3) Y, en fin, el art. 165.5 y 6 LGSS contempla otros periodos de inactividad asimilados a cotizados: el periodo de suspensión con reserva de puesto de trabajo previsto en el art. 48.8 ET, para supuestos de violencia de género; y el período por nacimiento y cuidado de menor que subsista a la fecha de extinción del contrato de trabajo, o que se inicie durante la percepción de la prestación por desempleo.

Por su parte, las medidas dirigidas a mejorar la cuantía se pueden clasificar en cuatro grupos.

1. El complemento por maternidad de las pensiones contributivas (art. 60 LGSS), del que se ha hecho un análisis crítico más arriba.

2. Los beneficios por cuidados de hijos/as o menores (art. 236 LGSS y RD 1716/2012). El beneficio consiste en computar como periodo cotizado aquel en el que se haya interrumpido la cotización por la extinción de la relación laboral o la finalización del cobro de prestaciones por desempleo «entre los nueve meses anteriores al nacimiento, o los tres meses anteriores a la adopción o acogimiento permanente de un menor, y la finalización del sexto año posterior a dicha situación»; se excluyen, desacertadamente, las personas trabajadoras autónomas ${ }^{44}$, quienes tienen una mayor dificultad para compatibilizar la crianza con el trabajo (Rodríguez, 2016: 133). La norma contabiliza como tiempo cotizado un máximo de doscientos setenta días por cada hijo o hija o persona menor adoptada o acogida, con el límite de cinco años por persona beneficiaria. Son personas beneficiarias cualquiera de «los progenitores, adoptantes o acogedores», si bien, cuando ambas partes cumplan los requisitos sólo se podrá conceder a una de ellas, y en caso de desacuerdo, a la madre, aunque, habría sido más razonable atribuir el beneficio al progenitor o progenitora que, efectivamente, hubiera estado al cuidado de la persona menor (Ballester, 2013: 209; Aragón, 2018: 71), o, de forma general, a quien se encuentre en la situación descrita (Blázquez, 2018: 81-82), para superar los estereotipos de género vinculados a los cuidados.

3. Excepciones a las reglas generales respecto de la integración de lagunas: a) En el período computable como cotizado en concepto de beneficio por cuidado de hijos/as o menores acogidos/as, la base de cotización a considerar estará constituida por el promedio de las bases de cotización de la persona beneficiaria correspondientes a los seis meses inmediatamente anteriores, y si no existieran, por el promedio de las bases de coti-

44 El cese de la actividad por cuenta propia o de la prestación por cese de actividad no está contemplado, si bien se podrá acceder al beneficio «cualquiera que sea el régimen que reconozca la prestación» (art. 5.3 RD 1716/2012, de 28 de diciembre), incluido el RETA. 
zación que resulten acreditadas (art. 9 RD 1716/2012, de 28 de diciembre). b) En el período de excedencia por cuidado de hijos/as y familiares la solución es idéntica (art. 7 RD 1335/2005, de 11 de noviembre). Si la excedencia hubiera estado precedida por una reducción de jornada ex 37.6 ET, las bases de cotización se computarán incrementadas hasta el $100 \%$ de la cuantía que hubiera correspondido si se hubiera mantenido la jornada de trabajo sin dicha reducción (art. 237.4 LGSS).

4. Incremento hasta el $100 \%$ de la base de cotización que hubiera correspondido de no haberse producido la reducción de jornada en supuestos de reducción de jornada por cuidados, con diferente alcance temporal según el caso (art. 237.3 LGSS). Los supuestos contemplados son el cuidado de menor de 12 ańos, de persona con discapacidad que no pueda valerse por sí misma, el cuidado del lactante entre 9 y 12 meses, y el cuidado de hijos/as con cáncer u otra enfermedad grave. Con esta medida se pretende contrarrestar, al menos parcialmente, una de las causas de la brecha prestacional: la reducción de jornada por cuidados, determinante de que el 70 \% del total del trabajo a tiempo parcial en España lo desarrollan mujeres.

\section{Conclusiones}

1. La gran diferencia entre sexos en materia de pensiones, cercana al 35\%, es debida principalmente a la persistencia de dos brechas de género, la laboral y la de cuidados. La combinación de ambas trae consigo salarios más bajos, que dan lugar a bases de cotización más reducidas, y vidas laborales interrumpidas por un desigual reparto del trabajo de cuidados dentro la familia, elementos que se traducen en pensiones femeninas más exiguas; aspectos que determinan un mayor índice de pobreza femenina durante todas las etapas vitales.

2. Ahora bien, la brecha laboral y la de cuidados no son las únicas circunstancias responsables de la desigualdad entre sexos en materia de pensiones, resultando esta, en parte, también imputable al ordenamiento jurídico y a los órganos que lo interpretan y aplican. La falta de perspectiva de género en el diseño del sistema español de Seguridad Social ha quedado reflejada en distintos pronunciamientos del Tribunal de Justicia de la Unión Europea que han declarado discriminatorias algunas de sus normas; lo que no deja de resultar paradójico dado que ha sido la propia Unión Europea la que ha impuesto a España «recomendaciones» para la superación de los efectos de la crisis económica-financiera de 2008, que se han traducido en un endurecimiento de las reglas de cálculo o revalorización de las pensiones y en el retraso de la edad de jubilación, medidas que han perjudicado especialmente a las mujeres por ser sus trayectorias laborales intermitentes y precarias. 
3. Las medidas dirigidas a retrasar la edad de jubilación hasta los 67 años, dificultar la jubilación anticipada, y establecer distintas fórmulas de envejecimiento activo que permitan compatibilizar la pensión de jubilación y el trabajo no han tenido en cuenta la realidad del trabajo femenino, con frecuencia penoso e inadecuado para ser desarrollado a una edad avanzada, ni las especiales dificultades que las mujeres de mayor edad encuentran para mantenerse en el mercado laboral por el efecto de la discriminación múltiple por razón de sexo y edad.

4. Dado que sus carreras de cotización son más exiguas, pocas mujeres podrán acreditar el largo período de cotización exigido para poder jubilarse a los 65 años, viéndose compelidas a hacerlo — si el mercado laboral se lo permitea edades más avanzadas que los hombres. Para aquellas que no puedan mantenerse en sus puestos de trabajo a una edad avanza, el aumento de la edad legal de jubilación generará penalizaciones cuando, en el mejor de los casos, puedan jubilarse anticipadamente, $y$, en el peor escenario, sean expulsadas del mercado de trabajo sin tener derecho a la pensión de jubilación contributiva.

5. La regulación de la jubilación anticipada voluntaria responde claramente a una visión androcéntrica del Derecho: 1) por no incluir el servicio social femenino - pero sí el servicio militar - a efectos de acreditar la carencia necesaria para acceder a la misma, previsión recientemente declarada discriminatoria por el Tribunal Supremo; 2) por impedir el acceso a la pensión si, tras aplicar los coeficientes reductores, el importe de la misma resultara inferior a la pensión mínima que correspondiese, requisito restrictivo que discrimina indirectamente a las mujeres al ser quienes perciben las pensiones más bajas; 3) y por prever como causa de jubilación anticipada voluntaria la extinción de la relación laboral de la mujer trabajadora como consecuencia de ser víctima de violencia de género, sin que a este colectivo especialmente sensible se le exonere - al menos parcialmente- del cumplimiento de los exigentes requisitos establecidos para el disfrute anticipado a la pensión.

6. La falta de perspectiva de género también se aprecia en los supuestos de anticipación de la edad de jubilación en trabajos de naturaleza excepcionalmente penosa, tóxica, peligrosa o insalubre (minería, trabajo en el mar, actividad taurina, trabajo ferroviario), de los que han quedado excluidos trabajos feminizados como los desarrollados por camareras de piso, trabajadoras al servicio del hogar familiar o cuidadoras profesionales de dependientes, sometidos todos ellos a elevados riesgos físicos derivados del sobreesfuerzo y, en ocasiones, a riesgos de carácter psicosocial y con altos índices de morbilidad.

7. Conforme a las vigentes reglas de cálculo de la base reguladora de la pensión de jubilación, se tendrán en cuenta las bases de cotización de los 25 años inmediatamente anteriores al mes previo al del hecho causante (con anterioridad eran 15), más difíciles de acreditar por parte de las mujeres que por parte de los hombres. Resultarán especialmente perjudicadas las trabajadoras autónomas y 
las empleadas de hogar, beneficiarias de las pensiones más bajas, a las que no se les extienden las reglas de integración de lagunas.

8. También discrimina indirectamente a las mujeres el incremento gradual del número de años cotizados para tener derecho al 100\% de la base reguladora, que, a la finalización del período transitorio, será de 37. Si bien la duración media de la vida laboral de las trabajadoras ha aumentado, habiendo pasado de 24,2 años en el 2000, a 32,8 años en 2017, todavía están lejos de los 37 años exigidos, coincidentes - precisamente- con el promedio de ańos cotizados por los hombres. Asimismo, pueden contribuir a mermar las ya exiguas pensiones femeninas el factor de sostenibilidad y el Índice de Revalorización del Sistema de Pensiones.

9. La limitación de la cuantía del complemento a mínimos constituye un ataque frontal a la garantía de suficiencia de las pensiones exigida por la CE, pues permitirá que personas que tengan derecho al complemento no alcancen la pensión de mínima vigente en cada momento. La medida posee, además, con un palmario impacto negativo de género, al ser las mujeres quienes perciben mayoritariamente dichos complementos.

10. Para reducir la brecha de género en la pensión de jubilación, se han diseńado distintas medidas correctoras encaminadas, con mayor o menor fortuna, a facilitar el cumplimiento del requisito de carencia y/o a mejorar la cuantía, pero sin incidir sobre la raíz de la desigualdad. En lo que se refiere, específicamente, al complemento por maternidad, lejos de promover la igualdad y la corresponsabilidad, supone un retroceso al asignar a las mujeres el rol de cuidadoras. Esta medida ha sido declarada directamente discriminatoria respecto de los hombres por la STJUE de 12 de diciembre de 2019, por no haber sido diseńada teniendo en cuenta las excepciones a la prohibición de toda discriminación directa por razón de sexo previstas por la Directiva 79/77CEE; como resultado de la sentencia, queda desactivado el efecto perseguido por la norma de reducir la brecha entre hombres y mujeres en la cuantía de las pensiones, por lo que la figura habrá de ser reformulada. A nuestro juicio, el TJUE ha olvidado apreciar que la medida también afecta negativamente a las mujeres al fomentar la perpetuación del rol de género de cuidados, que está en la base de la brecha prestacional.

11. Al sistema de pensiones español le está resultando extraordinariamente difícil diseñar una regulación de la pensión de jubilación en el trabajo a tiempo parcial que no discrimine indirectamente a las mujeres, como se infiere de distintas resoluciones del TJUE y del TC. Establecer períodos mínimos de cotización más amplios para quienes trabajan a tiempo parcial, fijar sistemas de cálculo de la carencia que introduzcan una doble penalización a estos colectivos o la falta de proporcionalidad de las reglas de cálculo de la cuantía que reducen el importe de la pensión en una proporción mayor a la correspondiente a los períodos de ocupación a tiempo parcial, son medidas que perjudican espe- 
cialmente a las mujeres por ocupar mayoritariamente estos trabajos, resultando contrarias a la Constitución Española y al Derecho de la Unión Europea.

12. Llegados a este punto, es evidente que diseñar un sistema de pensiones con perspectiva de género no es una opción sino una exigencia constitucional, del Derecho internacional y de la normativa de la Unión Europea, de lo que habrá de tomarse buena nota de cara a futuras reformas normativas en la materia. Por ello, cuando la actual crisis sanitaria obligue a repensar el modelo económico-productivo y el sistema de protección social y, particularmente, el régimen jurídico de la pensión de jubilación, no deberá quedar relegado ni perjudicado - como en otras ocasiones - el 50\% de la población. Para evitar que, una vez más, con motivo de una crisis, las mujeres se vean obligadas a replegarse en el ámbito privado, es preciso que Estados y empresas apuesten, más que nunca, por los cuidados y por la corresponsabilidad. Por ello, entre las grandes prioridades del Derecho del Trabajo y del Derecho de la Seguridad Social del siglo xxi deben situarse: el diseño de normas eficaces capaces de garantizar una equitativa redistribución de roles y responsabilidades en los ámbitos laboral y privado entre hombres y mujeres (Casas, 2019: 6), la dignificación del trabajo de cuidados, y el reforzamiento del Sistema para la Autonomía y Atención a la Dependencia.

\section{Bibliografía}

Aragón Gómez, Cristina (2018). «El impacto de la brecha salarial en la acción protectora del sistema de la Seguridad Social», Documentación Laboral, 115, 71.

Aparicio Tovar, Joaquín (2015). "La sostenibilidad como excusa para una reestructuración del sistema de Seguridad social», Cuadernos de Relaciones Laborales, vol. 33-2, 289.

Ballester Pastor, María Amparo (2011). «Reformas en materia de protección social e impacto de género. Un estudio crítico", Temas laborales: Revista andaluza de trabajo y bienestar social, 112, 74 .

Ballester Pastor, María Amparo (2013). La prestación por maternidad. Valencia: Tirant lo Blanch, 209.

BeARD, Mary (2018). Mujeres y poder. Un manifiesto (traducción castellana de Silvia Furió). Barcelona: Crítica, 13-51.

Blázquez Agudo, Eva María (2018). «Seguridad Social y discriminación intersectorial: la edad y la discapacidad desde la perspectiva de género", en BlázQuez Agudo, Eva María (ed.), Los ODS como punto de partida para el fomento de la calidad del empleo femenino. Madrid: Editorial Dykinson, 81-82.

Cabeza Pereiro, Jaime (2014). «Trabajo a tiempo parcial: reformas en materia laboral y de Seguridad Social», Actualidad Laboral, 9, 2.

Casas BaAmonde, María Emilia (2019). «Igualdad de género y Derecho del Trabajo y de la Seguridad Social: una integración inaplazable», Femeris, Vol. 4-2. Disponible en https://e-revistas.uc3m.es/index.php/FEMERIS/article/view/4761 (accedido 25-42020). 
Cavas Martínez, Faustino (2017). «Requisitos de acceso a la pensión de jubilación activa. Comentario a la STS, Social, de 30 de mayo de 2017, rcud. 2268/2015», Revista de derecho de la seguridad social, 13, 75.

Desdentado Aroca, Eva (2019). "Contrato de trabajo a tiempo parcial y Seguridad Social. Análisis y reflexiones críticas tras la Sentencia del Tribunal de Justicia de la Unión Europea de 8 de mayo 2019", Revista de Derecho Social, 86, 108-109.

Errandonea Ulazia, Elisabet (2015). «El Límite en la Cuantía de los Complementos por Mínimos:un Recorte en las Prestaciones Sociales de Cuantía Reducida», Trabajo, 33, 78. Disponible en http://rabida.uhu.es/dspace/bitstream/handle/10272/12798/ElLimite.pdf?sequence=2 (accedido: 24-7-2019).

Espín SAEZ, Maravillas (2016). "El contrato a tiempo parcial, ¿la conciliación en los tiempos de la precariedad?, Información Laboral, 12, 109.

Ferrando García, Francisca M.a (2018). «La discriminación múltiple e interseccional en el ámbito laboral», Estudios financieros. Revista de trabajo y seguridad social, 427, $19-54$.

Ferrando García, Francisca M.a (2020). «La circunstancia de parentesco en la tutela antidiscriminatoria laboral», Labos Revista de Derecho del Trabajo y Protección Social, 2, $1-23$.

Flor Fernández, María Luisa (2016). «Reflexiones en torno a la pensión de jubilación desde una óptica de género: el nuevo complemento por maternidad", Revista de Derecho Social, 76, 14-24.

García Romero, Belén (2019). «Retos pendientes en materia de igualdad: reducción del impacto de género en las pensiones de Seguridad Social», en Selma Penalva, Alejandra (ed.), Retos en materia de igualdad de género en el siglo XXI. Un análisis multidisciplinar. Madrid: Dykinson, 82.

Jiménez Hidalgo, Adoración (2018). «Juzgar con Perspectiva de Género en la Jurisdicción de lo Social», Ponencia impartida en las 2as. Jornadas Jurídicas de Derecho Laboral y Sindical del Gabinet Tècnic Jurídic de CCOO de Cataluña, sobre «La precariedad laboral: desigualdad y discriminación», Barcelona, 8 de noviembre del 2018. Disponible en http://www.mujeresjuezas.es/2019/01/14/juzgar-con-perspectiva-degenero-en-la-jurisidiccion-de-lo-social-novedoso-e-interesante-articulo-de-nuestrasocia-adoracion-jimenez-hidalgo/ (accedido: 11-4-2020).

Lousada Arochena, José Fernando (2016). «La integración de la perspectiva de género en la aplicación e interpretación de las normas por la jurisdicción social», Revista de Derecho Social, 76, 39.

Lousada Arochena, José Fernando (2020). El enjuiciamiento de género. Madrid: Dykinson, 11-155.

Martínez García, María Luisa (2017). «Maternidad y discriminación de las mujeres en el empleo», Anales de Derecho, Vol 35-2. Disponible en https://revistas.um.es/ analesderecho/article/view/295781 (accedido: 10-4-2020).

Molina Navarrete, Cristóbal (2020). «Brechas de género y sistema español de seguridad social: balance crítico y algunas propuestas de corrección», iQual. Revista de Género e Igualdad, 3, disponible en https://revistas.um.es/iqual/article/view/386571 (accedido: 16-4-2020).

Ortiz GonzÁlez-Conde, Francisco Miguel (2016). "Balance de las reformas en materia de jubilación durante las dos legislaturas de la crisis económica (2008-2015) al hilo de las recomendaciones europeas», Revista de derecho de la seguridad social, 6, 135. 
Poyatos Matas, Gloria (2019). «Juzgar con perspectiva de género: una metodología vinculante de justicia equitativa", iQual. Revista de Género e Igualdad, 2, disponible en https://revistas.um.es/iqual/article/view/341501 (accedido: 14-4-2020).

Rodríguez Egío, María Monserrate (2016). Hacia un trabajo autónomo decente. Albacete: Editorial Bomarzo, 133.

SAnZ SÁEz, Concepción (2018). «La discriminación en contra de las empleadas de hogar como forma de manifestación de las discriminaciones múltiples», Revista de Derecho Social, 83, 89.

Signorini, Elena (2020). «Un análisis con perspectiva de género de las pensiones en Italia», en Lopez Aniorte, M. a Carmen y García Romero, Belén (ed.), Envejecimiento, cuidados y dependencia: hacia una protección social con perspectiva de género, Aranzadi, Pamplona, 1-13.

SMART, Carol (1994). «La mujer del discurso jurídico», en Larrauri, Elena (ed.), Mujeres, Derecho penal y criminología, Siglo XXI de España Editores, 173. 